\title{
When Unfamiliarity Breeds Contempt: How Partisan Selective Exposure Sustains Oppositional Media Hostility
}

\author{
Erik Peterson and Ali Kagalwala* \\ Texas A\&M University \\ Department of Political Science
}

Forthcoming at the American Political Science Review

\begin{abstract}
Partisans hold unfavorable views of media they associate with the other party. They also avoid out-party news sources. We link these developments and argue that partisans assess out-party media based off negative and inaccurate stereotypes. This means cross-cutting exposure that challenges these misperceptions can improve assessments of out-party media. To support this argument, we use survey-linked web browsing data to show the public has hostile views of out-party news sources they rarely encounter. We conduct three survey experiments that demonstrate cross-cutting exposure to non-political or neutral political stories, forms of news widely available from online partisan sources, reduces oppositional media hostility. This explains how perceptions of rampant bias from out-party media coexist with more modest differences in the online content of major partisan news outlets. More broadly, we illustrate how negative misperceptions can sustain animus towards an out-group when people avoid encounters with them.
\end{abstract}

${ }^{*}$ Erik Peterson (erik.peterson@tamu.edu) is an Assistant Professor in the Department of Political Science at Texas A\&M University. Ali Kagalwala (alikagalwala@tamu.edu) is a graduate student in the Department of Political Science at Texas A\&M University. The authors thank Jamie Druckman, Johanna Dunaway, Jonathan Mummolo, Matthew Hayes, Shanto Iyengar, Mike Tomz, Michelle Torres, Paul Sniderman and participants at Rice University's Texas American Politics Symposium for helpful comments and Texas A\&M's College of Liberal Arts, Stanford's Laboratory for the Study of American Values, the Bill Lane Center for the American West, the Hoover Institution and the Knight Foundation for financial support. Replication files are available at the American Political Science Review Dataverse: https://doi.org/10.7910/DVN/CCV1NN. 
The reputations of media outlets have been caught up in rising public antipathy towards the opposing political party (see Mason 2018, Iyengar et al. 2019 for reviews of affective polarization). Partisans hold unfavorable views of media they associate with the other side, considering them biased and untrustworthy (Baum and Gussin 2007, Ladd 2012, Arceneaux and Johnson 2013, Stroud et al. 2014). Given the expansive news choice the contemporary media environment provides, these negative reputations are important for public opinion formation as they lead partisans to avoid out-party media, discount messages they encounter from them, and instead rely on information from sources they perceive as neutral or associated with their side (Iyengar and Hahn 2009, Stroud 2011, Goldman and Mutz 2011, Levendusky 2013a, Dorison et al. 2019, De Benedictis-Kessner et al. 2019).

When focusing on online news, this oppositional media hostility is puzzling. In contrast to cable television (Berry and Sobieraj 2013, Mutz 2015), economic pressure leads online partisan media to bundle political coverage with substantial amounts of non-political news (Hindman 2018, Munger ND) and constrains their ability to inject ideological slant into much of their political coverage (Gentzkow and Shapiro 2011). Content analysis of online news finds modest differences in the perceived slant of the typical political story from major partisan outlets, a departure from the "outrage" typically associated with them (Budak et al. 2016, Peterson et al. ND).

We resolve this puzzle by arguing that online partisan selective exposure sustains oppositional media hostility. We posit that, absent direct experience, the public assesses out-party media based off negative and inaccurate stereotypes. This means dislike of out-party media occurs despite, not because of, the coverage major online partisan media outlets provide. In turn, our argument implies that cross-cutting exposure that deviates from these stereotypes can improve assessments of out-party media by challenging inaccurate beliefs about their coverage that provide the basis for oppositional media hostility.

To support this argument, we use survey-linked web browsing data to show the public 
holds negative views of out-party news sources they rarely encounter. We then conduct three survey experiments with a combined sample of over 8,000 respondents to assess the effects of cross-cutting exposure. The first experiment assigns exposure to non-political coverage from an out-party or in-party source, which improves views of out-party media, but has limited effects for those encountering an in-party source. The second experiment shows cross-cutting exposure reduces oppositional media hostility only when it counters stereotypes of out-party news (i.e., when it is not political or offers a neutral portrayal of ongoing political events). In contrast, exposure to reputation-consistent political coverage (i.e., coverage hostile towards the source's political opponents) from out-party media does not reduce oppositional media hostility. Finally, the third experiment examines how people assess out-party media coverage. Along with others (Feldman 2011, Baum and Gussin 2007, Turner 2007), we find partisans engage in biased processing of news from out-party media, but show this is not powerful enough to completely inhibit responsiveness to the type of news these sources provide.

Our findings reveal the self-sustaining nature of political media reputations in the highchoice online environment. Given the perception a media outlet is associated with the other side, partisans are unlikely to encounter its content (e.g., Barnidge et al. 2020, Kaye and Johnson 2016, Goldman and Mutz 2011, Stroud 2011). This limits opportunities for the moderation experimentally induced in this study to occur when individuals choose the news they see. It also clarifies how oppositional media hostility coexists with content analyses that reveal more modest differences in the slant of the online coverage major partisan media sources provide. Finally, our attention to new types of cross-cutting exposure, representing forms of partisan media coverage widely available online, demonstrates lessons from cable television may not translate to the Internet, showing the benefits of using descriptive studies of media content to motivate experimental treatments.

While our evidence concerns assessments of partisan media, the dynamics we identify have suggestive implications for other studies of out-group hostility. We show that when 
individuals hold unfavorable views of a group and also avoid encounters with them, inaccurate stereotypes can sustain negative out-group affect. This illustrates that choice over whether out-group encounters occur impedes any ameliorative effects of intergroup contact (e.g., Allport 1948, Pettigrew and Tropp 2011), emphasizing the need to understand polarization in attitudes towards the opposition not only as the product of how people respond when they encounter out-groups, but as also based on their choices about whether or not to do so.

\section{Partisan Selective Exposure to Online News}

As the media environment has fragmented, the availability of partisan sources has sparked renewed interest in an old concept: selective exposure to political information (Lazarsfeld et al. 1944, Sears and Freedman 1967). While media in a low-choice environment provided a unifying experience (Mutz and Martin 2001), the Internet and cable television allow the public to seek news from sources aligned with their party (Iyengar and Hahn 2009, Stroud 2011, Levendusky 2013a, Davis and Dunaway 2016, De Benedictis-Kessner et al. 2019, Barnidge et al. 2020). However, a desire for party-congenial news is not the only contributor to media choice (Mummolo 2016, Messing and Westwood 2014, Bolsen and Leeper 2013, Iyengar et al. 2008, Hutchings 2003). Other factors, such as an interest in particular topics or social endorsements, constrain the emergence of complete partisan echo chambers even in high-choice online settings (Gentzkow and Shapiro 2011, Bakshy et al. 2015).

At the same time, when focusing on the content people encounter online, there is a divide in the sources frequented by members of different parties for political and election-related news (Garrett 2009, Flaxman et al. 2016, Guess ND, Peterson et al. ND). And, in a finding shared across many studies of online news use, partisans are unlikely to engage in crosscutting exposure to media outlets they associate with the other party. Instead the vast majority of their news consumption occurs on outlets visited by members of both parties or sources associated with their side (Gentzkow and Shapiro 2011, Table II; Stroud 2011, Ch. 
3; Bakshy et al. 2015, 1131; Peterson et al. ND, Table 1).

\section{Oppositional Media Hostility}

Like others associated with the opposing political party (e.g., Mason 2018, Iyengar et al. 2019), the public perceives out-party media as biased and views them in a negative light (Coe et al. 2008, Arceneaux et al. 2012, Stroud and Lee 2013, Kaye and Johnson 2016, Goidel et al. 2018). Partisans consider media associated with the other party to be a homogeneous "out-group" (Stroud et al. 2014) $\bigsqcup^{1}$ Because they do not encounter much of this coverage on their own, oppositional media hostility is shaped by rhetoric from politicians (Ladd 2012; Archer ND) and criticism of out-party media from the co-partisan news sources they do

frequent (Ladd 2012; Arceneaux and Johnson 2013, 146; Goidel et al. 2018). This is part of a broader pattern in which partisan news increases dislike of politicians and groups associated with the other party (Levendusky 2013b, Smith and Searles 2014; but see Druckman et al. 2019).

The sources of oppositional media hostility are important to understand because of its implications for news exposure and, consequently, public opinion formation. Holding a negative view of news sources they associate with the other party leads partisans to avoid their coverage (Barnidge et al. 2020, Dorison et al. 2019, Kaye and Johnson 2016). This reduces exposure to the types of cross-cutting news that might lead partisans to hold more moderate opinions on a variety of issues (Mutz and Martin 2001, Levendusky 2013a, Conroy-Krutz and Moehler 2015, De Benedictis-Kessner et al. 2019, Levy ND). Conversely, avoiding outparty media due to their negative reputations renders partisans more reliant on sources they perceive as neutral or associated with their side (Goldman and Mutz 2011, Stroud 2011). This has the potential to amplify the extremity of their policy views and negative attitudes

${ }^{1}$ This conceptualization of out-party media as an "out-group" motivates the suggestive connections we draw between our study and the intergroup contact literature. 
towards their political opponents (Davis and Dunaway 2016, Smith and Searles 2014, Levendusky 2013b) while limiting exposure to uncongenial news due to the "partisan filtering" co-partisan sources practice (Baum and Groeling 2008).

When considering the factors that shape this phenomenon, previous research finds crosscutting exposure to out-party media exacerbates oppositional media hostility. Arceneaux and Johnson (2013) show that forcing individuals to encounter news coverage from outparty media polarizes their view of these outlets (see also Coe et al. 2008, Arceneaux and Johnson 2015). Baum and Gussin (2007) demonstrate partisans are more likely to label a neutral piece of political news as biased when it is attributed to an out-party source (Turner 2007, Feldman 2011; see also Settle 2018, Ch. 6).

\section{A Disconnect Between Media Reputation and Online}

\section{News Coverage}

Studies of partisan media predominantly examine coverage from these sources that contains a clear ideological leaning and uncivil attacks on the opposing party (e.g., Arceneaux and Johnson 2013, Levendusky 2013a, Smith and Searles 2014, Mutz 2015, Druckman et al. 2019). There is evidence such coverage affects aspects of both mass opinion (e.g., Martin and Yurukoglu 2017, Lelkes et al. 2017) and elite behavior (e.g., Arceneaux et al. 2020).

Theoretical accounts offer good reasons for this focus. The goals of partisan media are distinct from the legacy sources that previously dominated the media marketplace. Rather than providing centrist coverage to attract the widest possible audience (Hamilton 2004), partisan media providers instead aim to cultivate a distinctive reputation to cater to audiences that prefer ideologically congenial political information (Mullainathan and Shleifer 2005) or to provide slanted coverage that influences political outcomes in their preferred direction (Prat 2018, Martin and McCrain 2019).

This leads partisan media to produce coverage that departs from what is available from 
other sources. When considering cable television, content analyses show news from partisan media differs from other sources by discussing politics with phrases that resemble those used by co-partisan politicians (Martin and Yurukoglu 2017) and directing "outrage" at political opponents (Berry and Sobieraj 2013, Smith and Searles 2013, Jamieson and Capella 2008) $\underbrace{2}$

While such partisan media coverage exists on the Internet (e.g., Lelkes et al. 2017), online partisan media face economic considerations that push them away from only providing reputation-consistent political news attacking the other side (Gentzkow and Shapiro 2011; Hindman 2018, Ch. 4; Munger ND). This introduces important, and understudied, variety into online partisan news that contrasts with the reputations of these outlets.

First, the pursuit of a large audience leads major online media, including partisan sources, to bundle political news with substantial amounts of non-political coverage (Hindman 2018, Munger ND). This is clear from the home pages of partisan websites which feature tabs for "entertainment" or "lifestyle" coverage (Fox News) and "culture \& arts" or "travel" news (Huffington Post). More systematically, Budak et al. (2016, Table 1; see also Peterson et al. ND) conduct a crowd-sourced content analysis of articles on news websites in the United States and find only $42 \%$ of their stories focus on politics. This extends to partisan sources, including Fox News (46\% of stories on politics) and Huffington Post (38\% of stories on politics) $\mathrm{H}^{3}$

Second, based on their limited reporting resources and the volume of coverage they produce, online partisan outlets are unable to introduce a distinct slant into all their political coverage (Gentzkow and Shapiro 2011, 1831-1832). As a result, they frequently re-purpose

\footnotetext{
${ }^{2}$ We note some partisan cable coverage, for instance during the daytime, also deviates from this profile. However, whether online or on cable, this content has not appeared in previous experiments on partisan media effects (e.g., Arceneaux and Johnson 2013).

${ }^{3}$ In our own content analysis we find $45 \%$ of the stories in a random sample of the coverage from these sites focused on politics and $55 \%$ on non-political topics (see Appendix A).
} 
wire service stories (Baum and Groeling 2008). While partisan sources selectively decide which stories to emphasize, this content means that, along with reputationally-consistent coverage attacking the other party, partisan websites contain many stories with the neutral tone and point-counterpoint format emphasized in wire coverage.

This difference between cable television and the Internet manifests in large-scale content analyses of online political news. Budak et al. (2016, 260) use crowd-sourcing to consider the slant of online news coverage. They find an ordering of news websites consistent with past research (e.g., Fox News is more right-leaning and Huffington Post more left-leaning than other major news websites), but conclude "the vast majority of political articles in most outlets are neutral."

To assess this for the context of this study, we conducted a content analysis of a random sample of 206 political articles that appeared on Fox News or the Huffington Post in 2018. We had the slant of each article (i.e., how positive or negative it was perceived as treating Democrats and Republicans) assessed by fifteen coders on Amazon's Mechanical Turk. This reveals some reputation-consistent coverage attacking the other party, but we also find $57 \%$ of the political articles on these websites were perceived as neutral in their treatment of the out-party. This neutral coverage is similar to wire copy in describing ongoing political events in a civil manner and departs from the ubiquitous attacks on the opposition present on partisan cable news (Berry and Sobieraj 2013) $t^{4}$

This discussion reveals substantial amounts of non-political and neutral political stories

${ }^{4}$ While the most prominent political coverage on these websites (which we determined based on whether a story would be immediately visible upon reaching the website's home page) contains a slightly lower share of neutral political stories (54\%), there remains a substantial portion of non-political and neutral political coverage among the stories with prominent placement. See Appendix A for this analysis. 
on partisan media websites $5^{5}$ Experimental studies of news choice, which consider the public's ability to select these types of stories from partisan outlets, account for this (Mummolo 2016; Messing and Westwood 2014; Stroud 2011, Ch. 3; Iyengar and Hahn 2009). But such content not been used when considering the effects of cross-cutting exposure.

\section{Cross-Cutting Exposure and Oppositional Media Hos-}

\section{tility}

Although they do not encounter much content from them, the public views out-party media through a negative, politically-focused lens ${ }^{6}$ Yet, much online partisan news contrasts with this reputation. We posit that cross-cutting exposure that runs against these expectations can reduce oppositional media hostility. Such exposure challenges preconceived views of out-party media as biased and uncivil — assessments which provide the basis for oppositional media hostility, but are lightly informed by experience with out-party sources - and indicates the partisan, uncivil coverage individuals expect is not as pervasive as they supposed. Ultimately, such cross-cutting exposure portrays out-party media in a favorable light.

We use this perspective to develop three hypotheses. We anticipate two forms of crosscutting exposure will reduce oppositional media hostility. First, non-political coverage from partisan sources breaks from the politically-focused perspective the public uses to assess them. This is a clear departure from political "outrage" and leads to our first hypothesis.7

\footnotetext{
${ }^{5}$ Sydnor (2018) shows that, holding message content fixed, text is less able to convey outparty hostility than audio-visual content, highlighting another distinction between partisan news consumption online and on cable television.

${ }^{6}$ We provide support for this claim about perceptions of partisan news in Experiment 2.

${ }^{7}$ These sources could introduce partisan slant into coverage of non-political topics (e.g., Settle 2018 on "implicit" political news). We address this in Experiments 2 and 3.
} 
Hypothesis 1: Cross-cutting exposure to non-political coverage will improve views of the out-party media source providing it.

Second, neutral political coverage - for instance, the stories partisan media outlets produce from wire copy - is not inflected with the harsh critiques of the opposition commonly associated with their political coverage 8 While this type of coverage may still be chosen selectively (Baum and Groeling 2008) and can influence policy opinion (Levendusky 2013a, De Benedictis-Kessner et al. 2019), it also departs from the stereotypical stories attacking the opposition expected from these outlets. This leads to our second hypothesis.

Hypothesis 2: Cross-cutting exposure to neutral political coverage will improve views of the out-party media source providing it.

Finally, our perspective leads us to expect that cross-cutting exposure that aligns with stereotypes about out-party media sources - encounters with hostile political coverage attacking the opposition in an uncivil manner - will not improve assessments of out-party news sources. In line with earlier research on cross-cutting exposure to such content (e.g., Arceneaux and Johnson 2015), we expect these encounters to further reduce views of out-party media. This leads to a third hypothesis.

Hypothesis 3: Cross-cutting exposure to hostile political coverage will worsen views of the out-party media source providing it.

\footnotetext{
${ }^{8}$ We later operationalize "neutral" coverage as stories perceived by coders to not favor either political party and "hostile" coverage as stories perceived to attack the other party.
} 


\section{Points of Contrast With Extant Research}

Before our empirical tests, we emphasize two ways our account departs from the extant literature. First, there is evidence the public engages in biased evaluations of political news. Studies of the "hostile media phenomenon" show people interpret neutral political coverage as biased against their side (Vallone et al 1985, Giner-Sorolla and Chaiken 1994, Gunther and Schmitt 2004). This extends to news with slant, as partisans perceive coverage supporting the out-party as more biased than coverage favoring their side (Feldman 2011, Coe et al. 2008). Biased processing is more pronounced when coverage comes from media associated with the other party (Baum and Gussin 2007, Turner 2007). This works against our expectations as partisans may perceive any story as biased when it comes from an out-party source

Second, there is evidence cross-cutting exposure increases oppositional media hostility (Arceneaux and Johnson 2015, Arceneaux et al. 2012, Coe et al. 2008), the opposite of the pattern we propose. In earlier studies this occurs because those who avoid out-party media are sensitive to hostile coverage. Accordingly, the forced cross-cutting exposure in some of our experiments may exacerbate these divides based on who it exposes to out-party news.

While previous studies do not directly test the effects of the new forms of cross-cutting exposure we consider here, they predict very different responses. Based on this we engage with these important alternatives in a multi-experiment test of our account. We use designs that both allow (Experiment 1) and do not allow (Experiment 2) respondents to choose whether to encounter political news from an out-party source. We ask them to evaluate coverage in a way that can reveal the biased processing of news seen in earlier studies (Experiment 3). This lets us adjudicate between our claims and previous work. 


\section{Fox News and Huffington Post as Exemplar Online Par- tisan Media}

We test our theory with an observational study and three survey experiments. For several reasons, these studies focus on Fox News and the Huffington Post. First, both are among the most visited news websites in the United States (Budak et al. 2016; Settle 2018, Ch. 6; Peterson et al. ND) $9^{9}$ Second, both websites have partisan audiences and reputations, allowing us to operationalize definitions of "in-party" and "out-party" media. When asked to evaluate the slant of news outlets on a 7-pt scale from "Liberal or pro-Democratic party bias" (1) to "Conservative or pro-Republican party bias" (7) in a 2018 YouGov survey, Huffington Post received an average rating of 2.5 and Fox News a rating of 5.7, placing the outlets at the extremes of major news sources and roughly equivalent distances, in opposing directions, from the mid-point of the scale (see Appendix B.2).

\section{Descriptive Evidence: Cross-Cutting Exposure Is Asso- ciated With Less Oppositional Media Hostility}

Our theoretical account rests, in part, on the notion that partisans have limited exposure to the out-party news sources they dislike. For this reason, we first consider the association between partisan selective exposure and oppositional media hostility. We use a survey, fielded by YouGov, from March 2018 in which the respondents had all installed a toolbar on their desktop web browser that tracked the websites they visited in the months before the survey (see Peterson et al. ND for another study using this approach). This lets us relate a respondent's online news exposure to their assessments of different media outlets.

${ }^{9} \mathrm{MSNBC}$ is a common choice as the left-leaning source in studies of cable partisan media, but as its website receives low levels of Internet traffic we use Huffington Post here. 
We examine views of Fox News and Huffington Post among 699 partisan survey respondents who visited at least one of the two websites in the browsing data. We consider the share of a respondent's visits to the two websites that went to the one associated with their party. For Republicans this is a respondent's number of visits to Fox News divided by their total number of visits to Fox News and Huffington Post. For Democrats it is their number of visits to Huffington Post divided by their total to the two websites. This captures selective exposure specific to this context, with higher values indicating less exposure to the source associated with the other party. We find limited cross-cutting exposure, as $73 \%$ of visits went to in-party sources. This divide is more pronounced among the most active quartile of news consumers, with $86 \%$ of visits from this group going to their in-party source.

Respondents placed Fox News and Huffington Post on feeling thermometers, with higher values indicating more affinity for the source. For Republicans the in-party outlet is Fox News and the out-party outlet is Huffington Post, the labels are reversed for Democrats. This reveals a large divide in views of partisan media. The in-party source received an average rating of 68.7 , while the out-party source received an average rating of 17.8 . 
Figure 1: Media Outlet Favorability by Use (Fox News and Huffington Post)

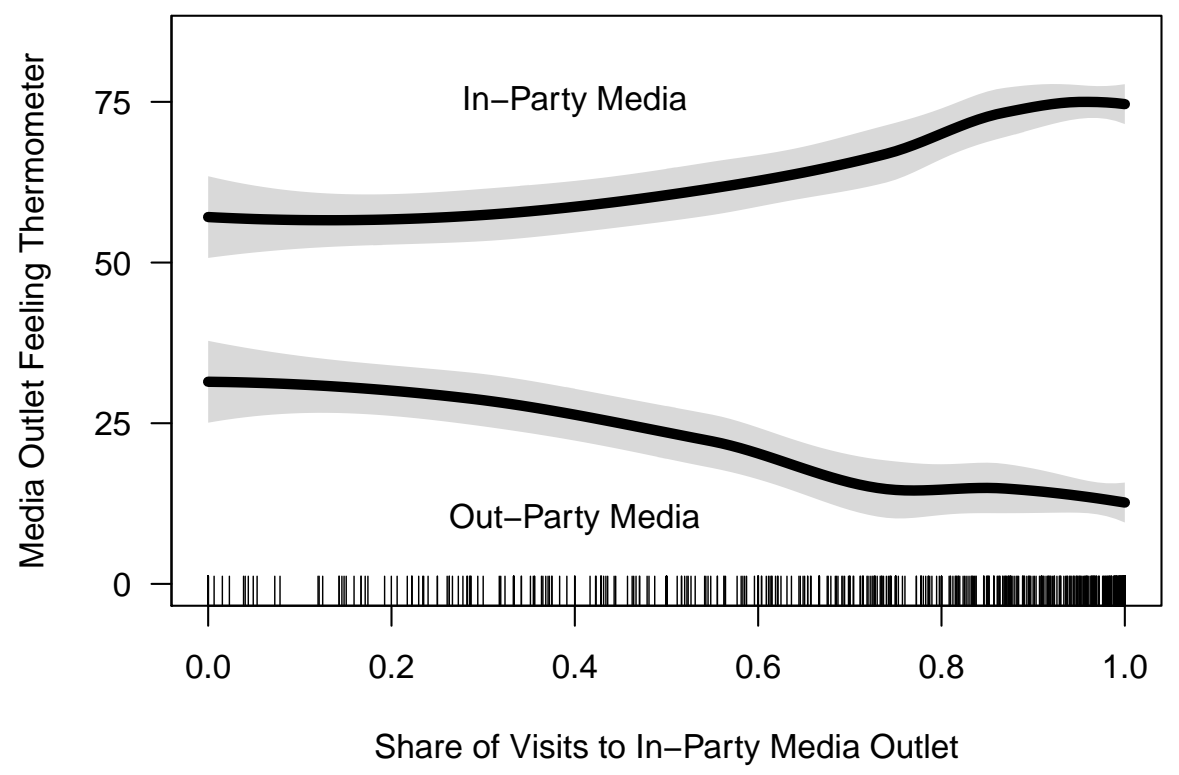

Note: Figure displays predicted values from LOESS regressions of partisan survey respondents' (n=699) approval of Fox News and Huffington Post on their relative use of the websites. The in-party source for Republicans is Fox News and for Democrats is Huffington Post. In-party visit share is the number of visits to their in-party site divided by their total number of visits to Fox News and Huffington Post.

Figure 1 displays the smoothed relationship between a respondent's media exposure and their assessments of the news outlets. It reveals that the greater an individual's share of visits to their in-party outlet, the more favorable their view of this in-party source and the more unfavorable their view of the out-party outlet. This establishes two points we build on in the rest of the paper. First, on average, partisans hold highly negative views of out-party sources they rarely encounter. Second, those with the most hostile views of out-party media have the least exposure to them 10

There is an association between partisan selective exposure and oppositional media hostility or, put otherwise, between cross-cutting exposure and favorable views of out-party ${ }^{10}$ Appendix B shows this pattern persists when separately analyzing Democrats and Republicans or those with varying amounts of news use and in regressions conditioning on partisanship, news use volume and demographics. 
media. However, our observational study indicates cross-cutting exposure is relatively limited and other studies of partisan media show those engaging in cross-cutting exposure differ from their co-partisans in many ways (e.g., weaker party loyalty) that could explain this association (Levendusky 2013a, Stroud 2010, see also Appendix Table B5) . For this reason, we now use survey experiments to randomly assign news exposure.

\section{Summary of Experimental Designs}

We use three survey experiments to consider the effects of partisan news exposure on news source reputation. Table 1 summarizes each experiment by characterizing its sample and the two main treatment arms that vary across the studies, which randomized the type of source and type of coverage respondents saw.

Table 1: Summary of Experimental Designs

\begin{tabular}{lllll}
\hline & Source & Sample size & Source Treatment & Coverage Treatment \\
\hline Exp. 1 & SSI & 1,879 & In-Party or Out-Party & Non-Political \\
Exp. 2 & Lucid & 4,250 & Out-Party & Non-Political, Neutral Political or Hostile Political \\
Exp. 3 & MTurk & 2,263 & Out-Party & Neutral Political or Hostile Political \\
\hline All studies focus on partisan respondents. \\
Experiments 1 and 2 include a control group with no news exposure.
\end{tabular}

Experiment 1, conducted in March 2017, examines the effects of exposure to non-political news among 1,879 partisan survey respondents recruited by SSI 11 Respondents were randomly assigned to encounter a non-political story from either an in-party or out-party source. This experiment tests whether counter-reputational coverage from a partisan source improves the public's view of it and compares the effects of in-party and out-party exposure.

Experiment 2 was conducted in August 2019 on 4,250 partisan respondents from the Lucid panel (see Coppock and McClellan 2019). It focused on the effects of exposure to an out-party source and broadened the coverage that was considered to include neutral political

\footnotetext{
${ }^{11}$ Respondents were quota sampled to align with census demographics on age, race, income and education. Characteristics of these respondents are available in Appendix C.
} 
coverage (i.e., political stories not perceived as slanted in favor of either political party) and hostile political stories (i.e., political coverage from the source that was perceived as critical of its opposing political party) in addition to non-political coverage. This allows for a full test of the effects of different forms of cross-cutting exposure in line with our hypotheses.

Finally, Experiment 3, also from August 2019, was conducted on 2,263 partisan respondents from Amazon's Mechanical Turk. The experiment compared the effects of cross-cutting political news (i.e., either neutral or hostile) from out-party sources. It included a wider set of outcomes to assess perceptions of different types of out-party coverage.

Combined, this multi-study approach allows a full test of our theoretical expectations and ensures key findings replicate in multiple studies. We now consider each study in turn.

\section{Experiment 1: Exposure to Non-Political News}

In Experiment 1, respondents began by selecting a topic they preferred reading about from a list of nine non-political areas $\sqrt{12}$ At this point some were assigned to a control group with no further news exposure and evaluated the media outlets with a feeling thermometer ${ }^{13}$ The other respondents read a story on the non-political topic they were interested in and were randomly assigned to see the story attributed to Fox News or Huffington Post. They saw the same non-political story regardless of the outlet to which it was attributed.

After reading the first story, respondents in the news exposure conditions selected a second story to read from the same outlet. Based on viewing the article's headline and first sentence, they chose between an additional non-political story, drawn from the ones they had not already seen, or a political story. This follow-up political story was randomly

\footnotetext{
${ }^{12}$ These categories were: Arts and Culture, Business, Entertainment News, Health and Wellness, Science, Sports, Style, Tech News and Travel. They were developed based on the non-political coverage available on popular news websites.

${ }^{13}$ Respondents were assigned to this control group with probability 0.2 .
} 
assigned to either be neutral coverage from the Associated Press or, in the style emphasized in prior examinations of partisan media (Berry and Sobieraj 2013, Levendusky 2013b), a piece of hostile coverage criticizing the opposition (e.g., a story attacking Democrats on Fox News). These follow-up stories were selected using a pre-test on Amazon's Mechanical Turk to ensure they were perceived in the intended manner ${ }^{14}$ After reading both articles, respondents evaluated the media outlets with a feeling thermometer.

The design of Experiment 1 accomplishes three things. First, it offers a chance to observe whether encountering non-political stories on a topic they care about, content particularly likely to induce cross-cutting exposure (Mummolo 2016), changes the public's views of outparty media. Second, it examines whether these effects occur when reminding respondents of the political news available from these websites while selecting a second article. Third, this offers the same observations for in-party sources, enabling us to consider the malleability of media reputations for outlets co-partisans have more experience with.

We note the treatment effects from this design are a composite of the random assignment to the initial, forced round of non-political exposure and the coverage available when respondents chose a second story. We took this approach to understand whether any positive effects of non-political news exposure can persist given a reminder of the political coverage commonly associated with these outlets when selecting the follow-up story. This somewhat complicates the interpretation of the effects in this study, but we note later experiments employ a design to more cleanly isolate the effects of non-political coverage on its own.

\footnotetext{
${ }^{14} \mathrm{We}$ assign respondents to one headline from a pool of potential stories with the appropriate characteristics to ensure our findings generalize across the different types of coverage in a given category. See Appendix C for the individual articles.
} 


\section{Experiment 1 Results: Views of In and Out-Party Media}

We examine the effects of exposure on feeling thermometer assessments of a respondent's in-party source (i.e., Fox News for Republicans and Huffington Post for Democrats), their out-party source (i.e., Huffington Post for Republicans and Fox News for Democrats), and the difference in evaluations of the in-party and out-party sources, measuring the divide in their view of these outlets. The design of Experiment 1 creates five conditions. The first is the control condition, those with no news exposure, which is the reference category in our analysis. The second category is those who read non-political coverage from an out-party source and then encountered a neutral political article when selecting a follow-up. The third contains those assigned a non-political article from an out-party source, who saw a partisan political article when selecting another to read. The fourth contains those who read coverage from an in-party news source and had a neutral political article available when selecting a follow-up. Finally, the fifth treatment category includes those who encountered an in-party source and were presented with a partisan follow-up article from that outlet.

Table 2: Media Outlet Thermometer Ratings by Exposure

\begin{tabular}{|c|c|c|c|}
\hline & In-Party Media & Out-Party Media & Difference \\
\hline \multirow[t]{2}{*}{ (Intercept) } & $62.67^{*}$ & $37.33^{*}$ & $25.35^{*}$ \\
\hline & $(1.31)$ & $(1.72)$ & $(2.01)$ \\
\hline \multirow[t]{2}{*}{ Out-Party (Neutral Followup) } & 0.19 & $8.28^{*}$ & $-8.09^{*}$ \\
\hline & $(1.77)$ & $(2.32)$ & $(2.72)$ \\
\hline \multirow[t]{2}{*}{ Out-Party (Partisan Followup) } & 0.24 & $8.99^{*}$ & $-8.75^{*}$ \\
\hline & $(1.74)$ & $(2.29)$ & $(2.68)$ \\
\hline \multirow[t]{2}{*}{ In-Party (Neutral Followup) } & $5.81^{*}$ & 3.20 & 2.61 \\
\hline & $(1.76)$ & $(2.30)$ & $(2.70)$ \\
\hline \multirow[t]{2}{*}{ In-Party (Partisan Followup) } & 2.63 & 3.31 & -0.68 \\
\hline & $(1.69)$ & $(2.22)$ & $(2.60)$ \\
\hline$N$ & 1879 & 1879 & 1879 \\
\hline \multicolumn{4}{|l|}{ Reference category is no news exposure } \\
\hline \multicolumn{4}{|l|}{ Models control for party } \\
\hline \multicolumn{4}{|l|}{ Standard errors in parentheses } \\
\hline${ }^{*}$ indicates significance at $p<0.05$ & & & \\
\hline
\end{tabular}


Table 2 regresses these outcomes on indicator variables for the treatment categories. We begin with the implications of out-party media exposure. The second column of Table 2 reveals that encountering the non-political coverage from an out-party source substantially improved that outlet's favorability. Relative to the control group, out-party source ratings improved both in the condition where the follow-up choice set included a neutral political article (8.3 points, $95 \%$ Confidence Interval $[3.6,12.9])$ and where a partisan political article was in the subsequent choice set (9.0 points, 95\% Confidence Interval [4.4, 13.6]). This supports our first hypothesis, that emphasizing a non-political dimension along which to evaluate out-party media improves views of them.

Consistent with this pattern, the third column of Table 2 shows exposure to non-political coverage from an out-party source also reduced the divide in an individual's views of in-party and out-party media in both conditions (-8.1, 95\% Confidence Interval [-13.5, -2.6] for the "Out-Party (Neutral Followup)" condition; -8.7, 95\% Confidence Interval [-14.1, -3.4] for the "Out-Party (Partisan Followup)" condition). To place these shifts in context, consider how the size of this gap changed across the experimental conditions. In the control group, the divide was 23.7 points. Pooling together the out-party exposure conditions, the divide fell to 15.2 points. In other words, exposure to non-political coverage from an out-party source produced a $35 \%$ decline in the divide over views of different media relative to the control.

Table 2 also shows the influence of non-political coverage on an outlet's reputation is substantially larger for out-party sources than in-party media. To summarize this, we compare the net improvement in the treated outlet's rating to the non-treated outlet's rating for each category (i.e., the pooled effect of the two out-party exposure conditions on the out-party/in-party thermometer difference relative to the pooled effect of the two in-party exposure conditions on the in-party/out-party thermometer difference) 15 The absolute effect of out-party non-political exposure, compared to in-party non-political exposure, is a

\footnotetext{
${ }^{15}$ Appendix Table $\mathrm{C} 4$ shows the regression pooling the in-party and out-party conditions.
} 
7.6 point improvement (95\% Confidence Interval $[2.2,12.9]$ ) in assessments of the treated source relative to the non-treated outlet. This shows cross-cutting exposure has distinctive consequences for media outlet approval relative to exposure to in-party outlets with which respondents have more familiarity and a higher baseline level of support.

Beyond these overall effects of in-party and out-party exposure, it is also important to note the non-consequences of the additional manipulation included in this experiment, the variation in the types of political news coverage that respondents saw while selecting a second story. This manipulation was included to see if a subsequent reminder of the hostile coverage available from out-party sources undermines any improvement in views towards them brought about by exposure to their non-political coverage.

Table 2 indicates exposure to out-party coverage, whether followed with a neutral or hostile political article, improved assessments of the out-party source and reduced the feeling thermometer divide between in-party and out-party media. There was no difference based on the follow-up political article that was available. For example, in terms of reducing the divide between in-party and out-party evaluations, the difference between the neutral and hostile followup conditions from the out-party source was small and not distinguishable from zero $(0.7,95 \%$ Confidence Interval $[-6.0,7.3])$. This shows the findings are robust to a reminder of the reputation-consistent coverage available from out-party media.

We suspect this finding is partially due to respondents' ability to avoid hostile political coverage from the out-party source if they wished. In Appendix $\mathrm{C}$ we show respondents more frequently avoided political articles from the out-party source when assigned to the hostile condition, limiting the time they spent with this coverage. This avoidance is consistent with earlier work on cross-cutting exposure to partisan media (Arceneaux and Johnson 2013). 


\section{Experiment 2: Effects of Cross-Cutting News Exposure}

Experiment 1 shows encountering non-political coverage from out-party media improves views of these outlets. However, it leaves open whether other types of cross-cutting exposure can accomplish this. Our expectation is that coverage that is inconsistent with the public's negative stereotypes of out-party media sources should improve views of them. This means, beyond non-political stories, neutral political coverage has this potential. In contrast, political stories consistent with the public's negative notions of out-party media coverage should not improve views of these sources.

Our second experiment considers the effects of different types of cross-cutting exposure. At the beginning of the survey, respondents indicated the type of non-political news they preferred. They were randomly assigned to four conditions ${ }^{16}$ First, the control group had no news exposure. Second, those in the non-political treatment encountered a story on their preferred topic from the out-party source (e.g., a Fox News story was "Italian church, cops dupe art thieves by swapping out original $\$ 3 \mathrm{M}$ masterpiece for fake"). Third, those in the neutral out-party condition encountered a political story assessed as neutral, in the sense it did not clearly favor or denigrate members of either party, by coders in a pre-test (e.g., a Fox News story was "DOJ announces release of 3,100 inmates as part of criminal reform push"). Fourth, those in the hostile out-party condition encountered a highly partisan story in which the news source criticized its opponents, again with a label validated by pre-testing (e.g., a Fox News story was "Ingraham: Left trying to destroy what it means to be American") 17

\footnotetext{
${ }^{16}$ We assign respondents to an out-party source using the party they provided when entering the Lucid panel, which was passed into our survey. This measure agrees with one collected at the end of our survey in $95 \%$ of cases. Results remain the same when we drop respondents with inconsistent panel and survey measures. See Appendix D.

${ }^{17}$ See Appendix D for a pre-test description and Appendix Tables D1 and D2 for the
} 
Like Experiment 1, respondents saw one story randomly selected from a pool of coverage in the assigned category, meaning our design does not hinge on any individual story.

This design makes several advances. First, unlike the initial experiment, all the coverage originally appeared on the site to which it was attributed. To the extent a website's partisan leanings intrude into its non-political coverage or seemingly neutral political stories in a way that is not captured in our pre-test, but which confirms the negative reputations of these websites, this offers a more realistic test of the ameliorative effects of cross-cutting exposure. Second, the broader set of out-party exposure conditions includes all forms of coverage relevant to our theory. Third, this forced exposure design provides a tough test of our expectation that neutral political coverage can improve views of out-party media. To the extent those who prefer to avoid out-party sources respond negatively to any political news from them, providing no opportunity to avoid it works against our theoretical expectations.

\section{Experiment 2 Results: Views of Out-Party Media}

We examine the effects of this exposure on feeling thermometer ratings of the out-party outlet and the difference between their ratings of in-party and out-party media. ${ }^{18}$ Due to the potentially smaller effects of neutral political coverage, relative to non-political stories, we control for pre-treatment covariates in the analysis to improve the precision of the treatment effect estimates. Before indicating their non-political news interests, respondents evaluated the partisan bias of several media sources on a seven-point scale. For the regressions in Table 3. we control for a respondent's party and their view of out-party source bias.

headlines of all articles used in the experiment.

${ }^{18}$ Since there was no in-party media exposure, we do not present the in-party media thermometer, but incorporate it into the difference measure. 
Table 3: Out-Party Media Ratings by Exposure Condition

\begin{tabular}{|c|c|c|}
\hline & Out-Party Media & Media Difference \\
\hline \multirow[t]{2}{*}{ (Intercept) } & $13.40^{*}$ & $52.97^{*}$ \\
\hline & $(0.98)$ & $(1.33)$ \\
\hline \multirow[t]{2}{*}{ Hostile Out-Party } & -0.43 & 0.35 \\
\hline & $(1.04)$ & $(1.41)$ \\
\hline \multirow[t]{2}{*}{ Neutral Out-Party } & $3.67^{*}$ & -2.53 \\
\hline & $(1.04)$ & $(1.42)$ \\
\hline \multirow[t]{2}{*}{ Non-Political Out-Party } & $4.83^{*}$ & $-3.70^{*}$ \\
\hline & $(1.04)$ & $(1.41)$ \\
\hline$N$ & 4250 & 4250 \\
\hline \multicolumn{3}{|c|}{ Reference category is no news exposure } \\
\hline \multicolumn{3}{|c|}{ Models control for party and pre-treatment views of out-party media bias } \\
\hline \multicolumn{3}{|l|}{ Standard errors in parentheses } \\
\hline \multicolumn{3}{|c|}{${ }^{*}$ indicates significance at $p<0.05$} \\
\hline
\end{tabular}

For the non-political treatments, our results align with Experiment 1. Exposure to a non-political story from the out-party source improved assessments of that source by 4.8 points (95\% Confidence Interval $[2.7,6.9])$ on the feeling thermometer scale and reduced the divide in assessments of in-party and out-party media sources by 3.7 points ( $95 \%$ Confidence Interval $[-6.5,-0.9])$. This amounts to a $12 \%$ reduction in the size of the divide in views of in-party and out-party media compared to the control group. The magnitude of these effects is smaller than Experiment 1, but we observe effects in the same direction when using real-world coverage from these sources. This experiment also did not require individuals to consume multiple stories, so the effect is only for one article.

Encountering neutral political news from an out-party source also improved assessments of it by 3.7 points (95\% Confidence Interval $[1.6,5.8]$ ) relative to the control. This shows encounters with political news from out-party media need not increase hostility and can improve views of these sources. This is consistent with our second hypothesis. However, this did not produce a detectable decline in the divide between in-party and out-party sources, though it is in the expected direction $(-2.5,95 \%$ Confidence Interval $[-5.4,0.3]){ }^{19}$

\footnotetext{
${ }^{19}$ When we pool this study and the third experiment in Appendix Table E4 we observe a
} 
Finally, we do not find support for our third hypothesis. Relative to the control condition, there is not a detectable drop in evaluations of out-party media for those exposed to hostile coverage from these sources $(-0.4,95 \%$ Confidence Interval $[-2.5,1.7])$, even as the direction of this pattern aligns with our expectation that this type of cross-cutting exposure would increase oppositional media hostility. This small treatment effect indicates the public evaluates out-party media sources similarly in the control group, where they saw no coverage, and the treatment condition where they encountered hostile out-party news. We interpret this as evidence that, when the public evaluates out-party media, they already have such hostile coverage in mind when forming their evaluations.

\section{Experiment 2 Results: Inaccurate Stereotypes of Partisan Media}

\section{Coverage}

These findings are consistent with our theory that neutral and non-political coverage from out-party media depart from the stereotypes of these sources. However, we have not directly measured these reputations. For this reason, after collecting primary outcomes in Experiment 2, we asked respondents in the control group to evaluate six headlines and rate the likelihood they would appear on one of the websites using a five-point scale from "not at all likely" (1) to "extremely likely" (5) 20

The headlines were randomly selected from stories used in the experiment, meaning we already characterized their topic and perceived slant in a pre-test. There are four headline categories: non-political stories, neutral political stories, political stories hostile towards Democrats and political stories hostile towards Republicans. Table 4 displays the average likelihood respondents perceived headlines in the different categories would appear on a website. For each website, we order the categories from the coverage perceived as having detectable decline in this outcome between the hostile and neutral exposure conditions.

${ }^{20}$ They were randomly assigned one of the websites to evaluate. 
the highest likelihood of appearing on the website to the coverage seen to have the lowest likelihood of appearing on it.

Table 4: Perceived Likelihood Headline Type Appears on Website

\begin{tabular}{l|ll} 
& Fox News & Huffington Post \\
\hline Most Likely to Appear & Hostile Towards Democrats (3.9) & Hostile Towards Republicans (3.6) \\
& Neutral Political (3.3) & Neutral Political (3.3) \\
& Hostile Towards Republicans (3.2) & Hostile Towards Democrats (3.0) \\
Least Likely to Appear & Non-Political (2.8) & Non-Political (2.9)
\end{tabular}

Note: In parenthesis the table displays the average perceived likelihood, measured on a five-point scale, that various categories of headlines appear on a website from control group respondents in Study 2 ( $\mathrm{n}=1,276)$.

Table 4 reveals people most prominently think of partisan news sources as providing hostile coverage attacking the other side, with this type of coverage receiving an average rating of 3.9 for Fox News and 3.6 for Huffington Post, a departure from our content analysis in which non-political coverage and neutral political stories are more common than this type of coverage ${ }^{21}$ In a finding that helps explain the influential effects of non-political exposure, such coverage was seen as the least likely to appear, with an average rating of 2.8 for Fox News and 2.9 for Huffington Post, despite its actual prominence on these websites. The headline classification task affirms our earlier claims about inaccuracies in perceptions of partisan news source reputations.

\section{Experiment 3: Effects of Cross-Cutting Political News}

The second experiment shows that, beyond non-political stories, encountering neutral political coverage from an out-party source improves views of it. However, we have not assessed how respondents evaluated these stories. For this reason, we conduct a third experiment randomly assigning respondents to see hostile or neutral out-party political news.

In this experiment respondents assessed the article in terms of its slant-how favorable

${ }^{21}$ The difference in perceived likelihood of appearance between these categories are statistically significant (see Appendix Tables D5 and D6). 
or unfavorable it was towards their party on a five-point scale. We then examine whether partisans distinguish different types of political coverage from out-party sources. Prior studies suggest the availability of source labels leads people to perceive neutral coverage from an out-party source as biased (Feldman 2011, Baum and Gussin 2007, Turner 2007). Experiment 3 also allows to observe whether our finding that neutral coverage improves views of out-party media replicates, and lets us use a multi-item outcome scale, which we describe in more detail later, to measure views of out-party media.

\section{Experiment 3 Results: Perceptions of Article Slant}

Table 5 displays the effects of this exposure on assessments of article slant. In the first column, we regress the respondent's slant rating on the treatment, with the outcome coded so higher values indicate a perception the coverage is negatively-slanted against the respondent's party. To provide a reference for how these changes align with the ratings from the pre-test, the second column substitutes the average slant rating the article received in the pre-test for a respondent's own rating. This indicates the difference in how respondents evaluated articles relative to the coders, who assessed them without a source label. Finally, the third column examines the difference between a respondent's rating of article slant and the average pre-test rating the article received. This considers whether the articles were evaluated differently in the pre-test, where an outlet's label was unavailable, and the third experiment, where the media source was prominently featured.

The first column of Table 5 shows respondents evaluated the neutral coverage as less slanted against their party. Assessments move from the upper bound of the five-point slant scale in the hostile out-party condition (4.4), to near the scale mid-point in the neutral condition (3.5), a difference of -0.95 points (95\% Confidence Interval $[-1.03,-0.87]$ ). Even when respondents read the full article with the source label available, they distinguished between different types of coverage. This complements the second experiment, offering an 
Table 5: Assessments of Out-Party Coverage Slant By Exposure

\begin{tabular}{lrrr}
\hline & Slant (Respondent Perception) & Slant (Coder Rating) & Difference \\
\hline (Intercept) & $4.41^{*}$ & $4.33^{*}$ & 0.08 \\
& $(0.05)$ & $(0.01)$ & $(0.05)$ \\
Neutral Out-Party & $-0.95^{*}$ & $-1.34^{*}$ & $0.39^{*}$ \\
& $(0.04)$ & $(0.01)$ & $(0.04)$ \\
\hline$N$ & 2263 & 2263 & 2263 \\
\hline Reference category is hostile out-party news exposure & \\
Models control for party and pre-treatment views of out-party media bias & \\
Standard errors in parentheses & & \\
$*$ indicates significance at $p<0.05$ & &
\end{tabular}

indication of why respondents improved their views of out-party sources when encountering neutral political coverage from them.

However, the second and third columns show our findings are not entirely at odds with earlier evidence of source label bias. While respondents perceived the neutral coverage as less slanted, they are not as responsive to this content as would be implied by the ratings the headlines received from the coders, who assessed them without a source label. Using the coder assessments of article hostility from the pre-test, the reputation-consistent articles received an average rating of 4.3 while the neutral articles received a rating of 3.0 , a difference of -1.34 points (95\% Confidence Interval [-1.36, -1.32]).

The third columns shows the implications of this bias. While they responded to the difference between the reputation-consistent and neutral articles, respondents in the third experiment still rated the neutral articles as 0.39 points (95\% Confidence Interval $[0.31$, 0.48]) more negatively slanted than the pre-test ratings implied. This reveals the distorted processing found in earlier studies, but shows it is not powerful enough to eliminate responsiveness to the type of content available from out-party media. This links our study to earlier work, while explaining why our findings depart from it in important ways. 


\section{Experiment 3 Results: Views of Out-Party Media}

In Table 6 we consider the effects of exposure to neutral out-party coverage, relative to hostile out-party coverage. The table's first column examines the treatment effect on the outparty media scale created from four survey items taken from previous studies of oppositional media hostility (e.g., Arceneaux and Johnson 2012). This provides a broader assessment of the out-party source then the previous experiments. These four items were the 101-pt feeling thermometer capturing overall views of the out-party outlet, a 4-pt scale evaluating the fairness of the out-party source from "Always tends to favor one side" to "Always deals fairly with all sides", a 7-pt scale where they were asked whether the out-party media outlet provided accurate information about politics and answered on a scale ranging from "Strongly disagree" to "Strongly agree" and a 3-pt scale where they were asked about the ideology of the out-party outlet and could answer it was "mostly liberal", "mostly conservative" or "neither in particular." These items were combined into a scale using principal components analysis, with the final outcome re-scaled to have a mean of zero and a standard deviation of one. Higher values on this outcome indicate a more positive view of the out-party outlet ${ }^{22}$

The second column considers the effects for the out-party media thermometer on its own, corresponding to the analysis in earlier sections. Finally, the third column examines the difference between in-party and out-party media evaluations.

\footnotetext{
${ }^{22}$ For more detail see Appendix Table D9.
} 
Table 6: Out-Party Media Ratings by Exposure Condition

\begin{tabular}{lcrr}
\hline & Out-Party Media (Scale) & Out-Party Media (Therm) & Media Difference (Therm) \\
\hline (Intercept) & $-0.60^{*}$ & $11.63^{*}$ & $48.55^{*}$ \\
& $(0.03)$ & $(1.05)$ & $(1.44)$ \\
Neutral Out-Party & $0.10^{*}$ & $2.07^{*}$ & $-3.42^{*}$ \\
& $(0.03)$ & $(0.87)$ & $(1.19)$ \\
\hline$N$ & 2263 & 2263 & 2263 \\
\hline Reference category is hostile out-party news exposure & \\
Models control for party and pre-treatment views of out-party media bias & \\
Standard errors in parentheses & & \\
${ }^{*}$ indicates significance at $p<0.05$ &
\end{tabular}

These findings align with Experiment 2. Relative to the hostile coverage, encountering neutral political coverage improved assessments of out-party media. Using the combined scale, displayed in the table's first column, we find exposure to neutral coverage from outparty media improved assessments of the outlet by 0.1 standard deviations ( $95 \%$ Confidence Interval $[.04, .16])$. Using only the feeling thermometer, encountering a neutral article from an out-party source improved evaluations by 2.1 points (95\% Confidence Interval $[0.3,3.8]$ ) relative to a hostile article. As the third column shows, this translated into a 3.4 point reduction (95\% Confidence Interval $[-5.8,-1.0])$ of the divide in an individual's assessments of in-party and out-party media. Relative to the condition with hostile out-party coverage, this is a $12 \%$ decrease in the size of the divide ${ }^{23}$

While, as in the second experiment, the magnitude of these effects is relatively small, they occur from a single instance of cross-cutting exposure. This improvement in views of out-party media, due to coverage widely available from partisan media in online settings, is a clear directional departure from earlier findings where out-party media exposure increased oppositional media hostility (Arceneaux and Johnson 2015).

\footnotetext{
${ }^{23}$ We observe the same pattern in in Appendix Table E4 when pooling comparable conditions from Experiments 2 and 3.
} 


\section{Discussion and Conclusion}

We argue that two forms of cross-cutting exposure, based on coverage widely available from online partisan media, can improve views of out-party news sources. To support this, we use a descriptive analysis of online news choice to show the public holds hostile views of outparty media they rarely encounter. We use three survey experiments to illustrate that crosscutting exposure can reduce oppositional media hostility. When focusing on reputationallyconsistent news from partisan media, the coverage that dominates public perceptions, our

results resemble earlier studies. However, when we examine the effects of non-political or neutral coverage, cross-cutting exposure reduces oppositional media hostility.

Our findings have important implications for understanding contemporary political communication. First, they illustrate how partisan selective exposure sustains oppositional media hostility. While much online partisan media coverage deviates from the outrage commonly associated with these sources, their reputations among out-partisans are negative enough that cross-cutting exposure is limited, allowing an exaggerated view of their coverage to underpin oppositional media hostility. This demonstrates how polarized media reputations can persist no matter what coverage these outlets provide. It also highlights a need to consider how media reputations are established. We expect messages from co-partisan politicians and media contribute, particularly when people do not encounter such media on their own (Ladd 2012, Archer ND, Peterson and Muñoz ND). This work should also consider the reputational consequences when media content becomes more extreme in a setting that was not formerly partisan, such as the expansion of Sinclair Media's ownership of local television stations (Martin and McCrain 2019).

Second, while the mechanism differs, our findings align with others showing the depolarizing effects of cross-cutting exposure for policy attitudes and views of the opposition (Levy ND, De Benedictis-Kessner et al. 2019, Conroy-Krutz and Moehler 2015). 
Third, we show that findings based on partisan cable television do not always translate to the Internet, where the delivery and content of partisan media may fundamentally differ (Sydnor 2018). It is important for future research to consider aspects of partisan media effects that do, and do not, generalize from cable to the Internet and use descriptive studies of online content to design experiments.

While our theory and evidence are confined to partisan media sources, our theoretical perspective suggests a channel through which inaccurate stereotypes can sustain out-group animus across many settings. When people hold negative views of an out-group and also avoid them, misperceptions can sustain out-group animus that would otherwise be attenuated by such encounters. For instance, there is evidence that misperceptions about the other party inflate affective polarization (Levendusky and Malhotra 2016, Ahler and Sood 2018, Lees and Cikara 2020, Moore-Berg et al. 2020, Druckman et al. ND). Our perspective suggests it is worthwhile to examine whether this stems from partisan homophily in an individual's interpersonal relationships (e.g., Mutz 2006, Rossiter 2020). In terms of explaining out-group animus, our study points to the importance of considering not only how encounters with an out-group influence opinion (e.g., as in assessments of the "intergroup contact hypothesis"; Allport 1954, Pettigrew and Tropp 2011), but also the choices people make about whether such encounters occur.

In closing, we note some considerations for assessing these findings. One limitation is that the effects of cross-cutting exposure we observe are relatively small. We view this as indicative of the difficulty in moving attitudes towards groups and individuals associated with the out-party, a pattern that manifests in prior studies of affective polarization (Levendusky 2018). These effects should also be understood in the context of a single encounter with an out-party source. Were individuals to engage in more substantial encounters of this type, the effects of cross-cutting exposure may be larger (for suggestive evidence see Stone et al. 2017). While we lack the measures to consider it here, we also suspect there may be heterogeneity 
in these effects. In particular, cross-cutting exposure may be more impactful for those with a dispositional avoidance of conflict, an important personality trait considered in other studies of media incivility (Mutz 2015, Sydnor 2019) and those with one-sided media diets that leave them with the limited prior exposure to out-party sources.

A second limitation is our focus on two news outlets. The reach and clear partisan reputations of Fox News and Huffington Post makes them important to consider, but potentially limits the generalizability of our findings if other partisan media sources do not provide these same types of counter-stereotypical coverage. However, previous content analysis of partisan media show even highly-partisan sources (e.g., Breitbart and Daily Kos) still provide some news coverage that is non-political or neutral, making our findings relevant to these outlets (Budak et al. 2016, Table 1; Sobieraj and Berry 2011, 32-33). Moreover, given partisan polarization in views of many mainstream news sources, and the particularly negative views of these outlets held by Republicans (Ladd 2012), our findings also suggest that exposure to coverage from mainstream sources that breaks from negative stereotypes about them could produce similar effects.

Finally, we emphasize our focus on attitudes towards out-party media neglects other important outcomes that online partisan media may influence (e.g., divides over perceptions of factual evidence, policy opinion). Indeed, we view the study of oppositional media hostility as important due to its implications for the media sources people use and how they are influenced by them. For instance, even as it fails to exacerbate oppositional media hostility, the more neutral political coverage from online partisan media we consider could affect partisans' policy views (Levendusky 2013a, Smith and Searles 2014, De Benedictis-Kessner et al. 2019). We also do not address other channels, such as social media, through which people encounter incivility online (Munger 2017). Understanding when and how online online partisan media influence public opinion formation remains an important topic. 


\section{References}

Ahler, Douglas J. and Gaurav Sood. 2018. "The Parties in Our Heads: Misperceptions about Party Composition and Their Consequences." Journal of Politics 80(3): 964-981.

Allport, Gordon G. 1954. The Nature of Prejudice. Perseus Books.

Arceneaux, Kevin, Johanna Dunaway, Martin Johnson and Ryan J. Vander Wielen. 2020. "Strategic Candidate Entry and Congressional Elections in the Era of Fox News." American Journal of Political Science 64(2): 398-415.

Arceneaux, Kevin, Martin Johnson and Chad Murphy. 2012. "Polarized Political Communication, Oppositional Media Hostility, and Selective Exposure." Journal of Politics 74(1): $174-186$.

Arceneaux, Kevin and Martin Johnson. 2015. "How Does Media Choice Affect Hostile Media Perceptions? Evidence from Participant Preference Experiments." Journal of Experimental Political Science 2(1): 12-25.

Arceneaux, Kevin and Martin Johnson. 2013. Changing Minds or Changing Channels? Partisan News in an Age of Choice. University of Chicago Press.

Archer, Allison. ND. "Attacking the Fourth Estate: The Nature and Effects of Political Leaders' War with the Press." In Leadership, Populism and Resistance (Eds. Krisitin M.S. Bezio and Al Goethals). Edward Elgar.

Bakshy, Eytan, Solomon Messing and Lada A. Adamic. 2015. "Exposure to Ideologically Diverse News and Opinion on Facebook." Science 348(6239): 1130-1132.

Barnidge, Matthew, Albert C. Gunther, Jinha Kim, Yangsun Hong, Mallory Perryman, Swee Kiat Tay and Sandra Knisely. 2020. "Politically Motivated Selective Exposure and Perceived Media Bias." Communication Research 47(1): 82-103.

Baum, Matthew and Phil Gussin. 2007. "In the Eye of the Beholder: How Information Shortcuts Shape Individual Perceptions of Bias in the Media." Quarterly Journal of Po- 
litical Science 3(1): 1-31.

Baum, Matthew and Tim Groeling. 2008. "New Media and the Polarization of American Political Discourse." Political Communication 25(4): 345-365

Berry, Jeffrey and Sarah Sobieraj. 2013. The Outrage Industry: Political Opinion Media and the New Incivility. Oxford University Press.

Bolsen, Toby and Thomas J. Leeper. 2013. "Self-Interest and Attention to News Among Issue Publics." Political Communication 30(3): 329-348.

Budak, Ceren, Sharad Goel and Justin M. Rao. 2016. "Fair and Balanced? Quantifying Media Bias Through a Crowdsourced Content Analysis." Public Opinion Quarterly 80(S1), $250-271$.

Conroy-Krutz, Jeffrey and Devra C. Moehler. 2015. "Moderation from Bias: A Field Experiment on Partisan Media in a New Democracy." Journal of Politics 77(2), 575-587.

Coe, Kevin, David Tewskbury, Bradley J. Bond, Kristin L. Drogos, Robert W. Porter, Ashley Yahn and Yuanyuan Zhang. 2008. "Hostile News: Partisan Use and Perceptions of Cable News Programming."' Journal of Communication 58(2): 201-219

Coppock, Alexander and Oliver A. McClellan. 2019. "Validating the Demographic, Political, Psychological, and Experimental Results Obtained From a New Source of Online Survey Respondents." Research \& Politics 6(1): 1-14.

Davis, Nicholas T. and Johanna Dunaway 2016. "Party Polarization, Media Choice, and Mass Partisan-Ideological Sorting." Public Opinion Quarterly 80(S1): 272-297.

De Benedictis-Kessner, Justin, Matthew Baum, Adam J. Berinsky and Teppei Yamamoto. 2019. "Persuading the Enemy: Estimating the Persuasive Effects of Partisan Media with the Preference-Incorporating Choice and Assignment Design." American Political Science Review 113(4): 902-916.

Dorison, Charles A., Julia A. Minson and Todd Rogers. 2019. "Selective Exposure Partly Relies on Faulty Affective Forecasts." Cognition 188: 98-107. 
Druckman, James N., S.R. Gubitz, Matthew Levendusky and Ashley Lloyd. 2019. "How Incivility on Partisan Media (De-)Polarizes the Electorate." Journal of Politics 81(1): 291-295.

Druckman, James N., Samara Klar, Yanna Krupnikov, Matthew Levendusky and John Barry Ryan. ND. "(Mis-)Estimating Affective Polarization" Journal of Politics Forthcoming.

Feldman, Lauren. 2011. "Partisan Differences in Opinionated News Perceptions: A Test of the Hostile Media Effect." Political Behavior 33(3): 407-432.

Flaxman, Seth R., Sharad Goel and Justin M. Rao. 2016. "Filter Bubbles, Echo Chambers, and Online News Consumption." Public Opinion Quarterly 80, 298-320.

Garrett, R. Kelly. 2009. "Echo Chambers Online?: Politically Motivated Selective Exposure Among Internet Users." Journal of Computer-Mediated Communication 14(2): 265-285.

Gentzkow, Matthew and Jesse M. Shapiro. 2011. "Ideological Segregation Online and Offline." Quarterly Journal of Economics 126(4): 1799-1839.

Giner-Sorolla, Roger and Shelly Chaiken. 1994. "The Causes of Hostile Media Judgments." Journal of Experimental Social Psychology 30(2): 165-180.

Goidel, Kirby, Spencer Goidel and Nicholas T. Davis. 2018. "Changes in Perceptions of Media Bias." Working Paper. http://www.nicholastdavis.com/wp-content/uploads/2018/ 04/media-bias-w-authors.pdf

Goldman, Seth K. and Diana C. Mutz. 2011. "The Friendly Phenomenon: A Cross-National Analysis of Cross-Cutting Exposure." Political Communication 28(1): 42-66.

Gunther, Albert C. and Kathleen Schmitt. 2004. "Mapping Boundaries of the Hostile Media Effect." Journal of Communication 54(1): 55-70.

Guess, Andrew M. ND. "(Almost) Everything in Moderation: New Evidence on Americans' Online Media Diets." American Journal of Political Science Forthcoming.

Hamilton, James T. 2004. All the News That's Fit To Sell: How the Market Transforms Information Into News. Princeton University Press. 
Hindman, Matthew. 2018. The Internet Trap: How the Digital Economy Builds Monopolies and Undermines Democracy. Princeton University Press.

Hutchings, Vincent L. 2003. Public Opinion and Democratic Accountability: How Citizens Learn about Politics. Princeton University Press.

Iyengar, Shanto and Kyu S. Hahn. 2009. "Red Media, Blue Media: Evidence of Ideological Selectivity in Media Use." Journal of Communication 59(1), 19-39.

Iyengar, Shanto, Kyu S. Hahn, Jon Krosnick and John Walker. 2008. "Selective Exposure to Campaign Communication: The Role of Anticipated Agreement and Issue Public Membership." Journal of Politics 70(1): 186-200.

Iyengar, Shanto, Yphtach Lelkes, Matthew Levendusky, Neil Malhotra and Sean J. Westwood. 2019. "The Origins and Consequenes of Affective Polarization in the United States." Annual Review of Political Science 22, 129-146.

Jamieson, Kathleen Hall and Joseph N. Cappella. 2008. Echo Chamber: Rush Limbaugh and the Conservative Media Establishment. Oxford University Press.

Kaye, Barbara K. and Thomas J. Johnson. 2016. "Across the Great Divide: How Partisanship and Perceptions of Media Bias Influence Changes in Time Spent with Media." Journal of Broadcasting \& Electronic Media 60(4): 604-623.

Ladd, Jonathan. 2012. Why Americans Hate the Media and How it Matters. Princeton University Press.

Lazarsfeld, Paul, Bernard Berelson and Hazel Gaudet. 1944. The People's Choice: How the Voter Makes Up His Mind in a Presidential Campaign. Columbia University Press.

Lees, Jeffrey and Mina Cikara. 2020. "Inaccurate Group Meta-Perceptions Drive Negative Out-Group Attributions in Competitive Contexts." Nature Human Behaviour 4: 279-286.

Lelkes, Yphtach, Gaurav Sood and Shanto Iyengar. 2017. "The Hostile Audience: The Effect of Access to Broadband Internet on Partisan Affect." American Journal of Political Science 61(1): 5-20. 
Levendusky, Matthew. 2018. "Americans, Not Partisans: Can Priming American National Identity Reduce Affective Polarization?" Journal of Politics 80(1): 59-70.

Levendusky, Matthew. 2013a. How Partisan Media Polarize America. University of Chicago Press.

Levendusky, Matthew. 2013b. "Partisan Media Exposure and Attitudes Toward the Opposition." Political Communication 30(4): 565-581.

Levendusky, Matthew and Neil Malhotra. 2016. "(Mis)perceptions of Partisan Polarization in the American Public." Public Opinion Quarterly 80(S1): 378-391.

Levy, Ro'ee. ND. "Social Media, News Consumption and Polarization: Evidence from a Field Experiment." American Economic Review Forthcoming.

Martin, Gregory J. and Ali Yurukoglu. 2017. "Bias in Cable News: Persuasion and Polarization." American Economic Review 107(9): 2565-2599.

Martin, Gregory J. and Joshua McCrain. 2019. "Local News and National Politics." American Political Science Review 113(2): 372-384.

Mason, Lilliana. 2018. Uncivil Agreement: How Politics Became Our Identity. University of Chicago Press.

Messing, Solomon and Sean J. Westwood. 2014. "Selective Exposure in the Age of Social Media." Communication Research 41(8), 1042-1063.

Moore-Berg, Samantha L., Lee-Or Ankori-Karlinsky, Boaz Hameiri and Emile Bruneau. 2020. "Exaggerated Meta-Perceptions Predict Intergroup Hostility Between American Political Partisans." Proceedings of the National Academy of Sciences 117(26): 1486414872.

Mullainathan, Sendhil and Andrei Shleifer. 2005. "The Market for News." American Economic Review 95(4): 1031-1053.

Mummolo, Jonathan. 2016. "News from the Other Side: How Topic Relevance Limits the Prevalence of Partisan Selective Exposure." Journal of Politics 78(3), 763-773. 
Munger, Kevin. 2017. "Tweetment Effects of the Tweeted: Experimentally Reducing Racist Harassment." Political Behavior 39(3): 629-649.

Munger, Kevin. ND. "All the News That's Fit to Click: The Economic of Clickbait Media." Political Communication Forthcoming.

Mutz, Diana C. 2015. In-Your-Face Politics: The Consequences of Uncivil Media. Princeton University Press.

Mutz, Diana, C. 2006. Hearing the Other Side. Cambridge University Press.

Mutz, Diana, C. and Paul S. Martin. 2001. "Facilitating Communication Across Lines of Political Difference: The Role of Mass Media." American Political Science Review 95(1), 97-114.

Peterson, Erik, Sharad Goel and Shanto Iyengar. ND. "Partisan Selective Exposure in Online News Consumption: Evidence from the 2016 Presidential Campaign." Political Science Research \& Methods Forthcoming.

Peterson, Erik and Manuela Muñoz. 2020. "'Stick to Sports': Evidence from Sports Media on the Origins and Consequences of Newly Politicized Attitudes." Working Paper. https: //osf.io/preprints/socarxiv/dr397/

Pettigrew, Thomas F. and Linda R. Tropp. 2011. When Groups Meet: The Dynamics of Intergroup Contact. Psychology Press.

Prat, Andrea. 2018. "Media Power." Journal of Political Economy 126(4): 1747-1783.

Prior, Markus. 2007. Post-Broadcast Democracy. Cambridge University Press.

Rossiter, Erin. 2020. "The Consequences of Interparty Conversation on Outparty Affect and Stereotypes." Working Paper. http://erossiter.com/files/conversations.pdf

Sears, David O. and Jonathan L. Freedman 1967. "Selective Exposure to Information." Public Opinion Quarterly 31(2): 194-213.

Settle, Jaime E. 2018. Frenemies: How Social Media Polarizes America. Cambridge University Press. 
Smith, Glen and Kathleen Searles. 2014. "Who Let The (Attack) Dogs Out? New Evidence For Partisan Media Effects." Public Opinion Quarterly 78(1): 71-99.

Smith, Glen and Kathleen Searles. 2013. "Fair and Balanced News or a Difference of Opinion? Why Opinion Shows Matter for Media Effects." Political Research Quarterly 66(3): 671-684.

Sobeiraj, Sarah and Jeffrey Berry. 2011. "From Incivility to Outrage: Political Discourse in Blogs, Talk Radio and Cable News." Political Communication 28(1): 19-41.

Stone, Daniel F., Drew Van Kuiken and Justin Wallace. 2017. "Extended Exposure to Diverse News: Evidence From a Campus Project." Working Paper. https://dx.doi. org/10.2139/ssrn.3049015

Stroud, Natalie Jomini. 2010. "Polarization and Partisan Selective Exposure." Journal of Communication 60(3): 556-576.

Stroud, Natalie Jomini. 2011. Niche News. Oxford University Press.

Stroud, Natalie Jomini and Jae Kook Lee. 2013. "Perceptions of Cable News Credibility." Mass Communication and Society 16(1): 67-88.

Stroud, Natalie Jomini, Ashley Muddiman and Jae Kook Lee. 2014. "Seeing Media as Group Members: An Evaluation of Partisan Bias Perceptions." Journal of Communication 64(5): 874-894.

Sydnor, Emily. 2019. Disrespectful Democracy: The Psychology of Political Incivility. Columbia University Press.

Syndor, Emily. 2018. "Platforms for Incivility: Examining Perceptions Across Media." Political Communication 35(1): 97-116.

Turner, Joel. 2007. "The Messenger Overwhelming the Message: Ideological Cues and Perceptions of Bias in Television News." Political Behavior 29(4): 441-464. Vallone, Robert P., Lee Ross and Mark R. Lepper. 1985. "The Hostile Media Phenomenon." Journal of Personality and Social Psychology 49(3): 577-585. 
Supporting Information for:

"When Unfamiliarity Breeds Contempt: How Partisan Selective Exposure Sustains Oppositional Media Hostility" 


\section{Contents}

\begin{tabular}{|lll}
\hline A Appendix A: Content Analysis of Online Partisan Media Coverage & 1
\end{tabular}

A.1 Political and Non-Political News from Online Partisan Media . . . . . . . . . 1

A.2 Coverage by Prominence . . . . . . . . . . . . . . . . . . . . 3

A.3 Slant of Political News from Online Partisan Media . . . . . . . . . . . . . . 3

B Appendix B: Descriptive Study of Partisan Selective Exposure and Oppo$\begin{array}{ll}\text { sitional Media Hostility } & 7\end{array}$

B.1 Descriptive Study Demographics. . . . . . . . . . . . . . . . . . . . . 7

B.2 Fox News and Huffington Post Reputations. . . . . . . . . . . . . . . 8

B.3 Relating News Exposure and Oppositional Media Hostility . . . . . . . . . . 9

B.4 Predicting Selective Exposure . . . . . . . . . . . . . . . . . . . . . . . . . 12

\begin{tabular}{|ll}
\hline C Appendix C: Additional Material for Experiment 1 & 13
\end{tabular}

C.1 Experiment 1 Demographics . . . . . . . . . . . . . . . . . . . . . . 13

C.2 Experiment 1 Article Selection $\ldots \ldots \ldots \ldots$

C.3 Supplementary Analysis: Pooling In-Party and Out-Party Conditions . . . . 16

C.4 Supplementary Analysis: News Choice as Outcome . . . . . . . . . . . . . . 17

\begin{tabular}{lll}
\hline D Appendix D: Additional Material for Experiments 2 and 3 & 20
\end{tabular}

D.1 Experiments 2 and 3 Article Selection . . . . . . . . . . . . . . . 20

D.2 Experiment 2: Additional Material . . . . . . . . . . . . . . . . . 22

D.2.1 Experiment 2 Demographics . . . . . . . . . . . . . . . . . . . 22

D.2.2 Supplementary Analysis: Consistent Partisans Only . . . . . . . . . . 23

D.2.3 Supplementary Analysis: Differences in Perceived Content (Pairwise Tests of Differences $) \quad \ldots \ldots \ldots \ldots \ldots \ldots$ 
D.2.4 Supplementary Analysis: Reputations Among Out-Partisans Only . . 25

D.3 Experiment 3: Additional Material . . . . . . . . . . . . . . . . . . . . 26

D.3.1 Experiment 3 Demographics . . . . . . . . . . . . . . . . . 26

D.3.2 Additional Outcome Measures . . . . . . . . . . . . . . . . . . . . . . 26

\begin{tabular}{|ll}
\hline E Appendix E: Pooled Analysis of Experiments & 28
\end{tabular}

E.1 Pooled Effects of Non-Political Exposure . . . . . . . . . . . . . . . . . . . . 28

E.2 $\quad$ Pooled Effects of Neutral Political Exposure . . . . . . . . . . . . . . . . . . 29 


\section{A Appendix A: Content Analysis of Online Partisan Media Coverage}

We rely heavily on a content analysis of online news coverage conducted by Budak et al. (2016) to motivate our experiments. They find partisan news websites 1) offer substantial amounts of non-political news and 2) offer substantial amounts of neutral political coverage. In both cases, this contrasts with the hostility that predominates on cable television and emphasized in prior studies of cross-cutting exposure to partisan media.

In this section we supplement Budak et al's analysis and present the results of our own, independent content analysis of the online news coverage of the two partisan media outlets we consider here: Fox News and the Huffington Post. These results align with Budak et al's (2016) study and demonstrate the need to account for non-political and neutral political coverage in studies of cross-cutting exposure to partisan media sources online.

We begin by sampling coverage that received prominent placement on the home pages of foxnews.com and huffingtonpost.com on the following randomly selected days during 2018: $2 / 26,4 / 21,6 / 8,7 / 13,8 / 2,8 / 22,9 / 6,9 / 27,12 / 5$ and $12 / 16$.

We used the Internet Archive's Wayback Machine to examine the homepage at the closest capture to 12:00 PM. We recorded the headlines with prominent placement on the homepage, producing a sample of 461 headlines (246 from Fox News and 215 from Huffington Post).

\section{A.1 Political and Non-Political News from Online Partisan Media}

We use crowd-sourcing to consider the political and non-political coverage on these sites. Each headline was assessed by five coders from Amazon's Mechanical Turk. 47 total workers 
labeled articles. They were required to have a 95\% approval rating on previous HITs, have completed at least 500 total HITs and pass a political knowledge quiz.

Coders placed headlines into nine categories: U.S. Domestic Politics, International Politics, Business, Entertainment, Health, Science, Sports, Travel, and Other. Definitions and examples were provided for each topic. They separately indicated whether the article mentioned Donald Trump or crime to capture "soft" news with political relevance.

We consider an article "political" if it was placed in the U.S. Domestic Politics or International Politics categories OR if the article mentioned Donald Trump or crime. If an article did not meet these criteria, we consider it non-political. This scheme has a Krippendorf's alpha of 0.68 . Four or more coders agreed on the label in $88 \%$ of cases. To provide a final label we use a majority vote among coders. We consider an article non-political if three or more coders placed it in this category and otherwise consider it political.

Based on these final labels, $44 \%$ of the coverage on Fox News focuses on politics and $46 \%$ of the coverage on Huffington Post focuses on politics. Here our results align with those of Budak et al. (2016). Most importantly, this means over half the coverage from these online partisan news sources is not focused on politics and instead touches on non-political topics such as entertainment news (e.g., coverage of celebrities, movies and television shows).

To see how this looks, two non-political headlines featured on Huffington Post were "When Skin Care Is Also Self-Care" and "Gwyneth Paltrow Takes Credit For Yoga Boom. Twitter Bent Out Of Shape." Two non-political headlines on Fox News were "Sridevi, Bollywood leading lady of '80s and '90s, dies at 54" and "Ryan of ToysReview, 7, is YouTube's highestpaid star." Such non-political coverage is a departure from the reputations of these sources. 


\section{A.2 Coverage by Prominence}

While we took articles that appeared on each sources home page, the previous section does not consider the placement of these articles on the homepage. For this reason, we separate the articles into two groups, "prominent articles" which would be immediately visible upon visiting the website and "other articles" that would require scrolling to see.

Table A1: Share of Article Types on Partisan Websites by Prominence

\begin{tabular}{rrrr}
\hline & Non-Political & Neutral Political & Hostile Political \\
\hline Prominent Articles & 0.50 & 0.27 & 0.23 \\
Other Articles & 0.61 & 0.24 & 0.15 \\
\hline
\end{tabular}

Table A1 reproduces our results, using the same rules as the preceding section, separately for the prominent and other articles. The prominent articles are more political and more hostile than those with less emphasis. However, even given this, there are substantial amounts of non-political coverage and neutral political coverage among the prominent stories.

\section{A.3 Slant of Political News from Online Partisan Media}

After the initial round of coding that labeled an article's overall category, we took articles placed in the political category and had them assessed in terms of their partisan slant. Each of the 206 political articles (107 from Fox News and 99 from Huffington Post) received labels from fifteen coders on Amazon's Mechanical Turk. The requirements for coders to become eligible for this task were the same as the topic classification task.

After evaluating the headline and first 150 words of the article, coders placed it on a 5-point scale rating the bias towards Republicans and Democrats. Negative numbers indicate an article was perceived as very $(-2)$ or somewhat $(-1)$ negative towards a partisan group, positive headlines indicate a headline is very (2) or somewhat (1) favorable towards a partisan group and ratings of zero indicate a headline is neutral towards a partisan group. 
Figure A1 displays the average rating each of these political articles receive. As a point of reference, we also include points indicating perceptions of the articles later used in our hostile out-party and neutral political coverage treatments into this content analysis, which were evaluated at the same time as this random sample of partisan news articles. This shows how the experimental treatment categories compare to the typical coverage available from these news sources. These results are displayed in Figure A1.

Figure A1: Coder Perceptions of Slant in Coverage from Online Partisan Media
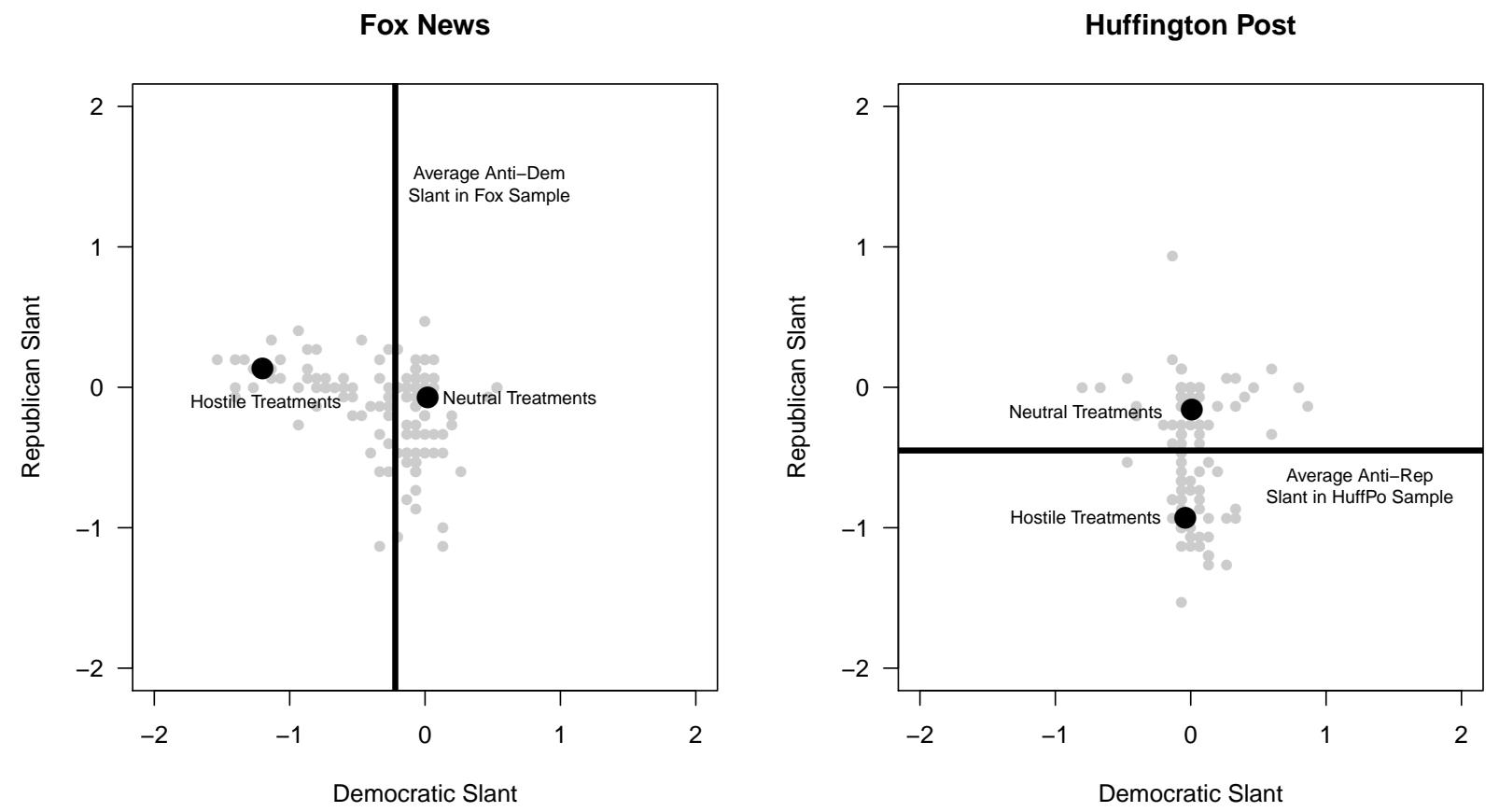

Note: We plot each political article's mean assessment based on the rating it received from 15 coders on Amazon's Mechanical Turk. The solid lines indicates the average political article's rating, in terms of its perceived slant against the out-party. The two labeled points are the average ratings received by the articles later used to represent those categories in our experimental treatments

We find evidence that the political coverage provided by these outlets is perceived as slanted in a manner consistent with their reputations, but the difference between these outlets is relatively muted. The average political article in the Fox News sample has a perceived slant 
of -.22 towards Democrats, indicating a slight hostility towards this group. Similarly, the average political article from Huffington Post has a perceived slant of -.45 towards Republicans. In this respect, our findings align with what Budak et al. (2016) find in their content analysis of article slant from online news sources in general.

While there is a range of coverage from these sources, and their coverage remains distinct in ways relevant for political information and policy opinion, the scope of our investigation here is on their treatment of the out-party. This content analysis shows the typical political article from these websites is more similar to the "neutral" experimental treatments we later employ than to the "hostile" experimental treatments that align with the reputations of these partisan news sources (we discuss the process used to select news articles for the experimental treatments in Appendix C and D). For Fox News, the hostile treatments we consider in our experiment are more negative towards the out-party than all but one of the news articles from our sample. For Huffington Post, the hostile articles are more negative towards the out-party than $77 \%$ of the articles in this sample.

Under a fairly stringent threshold of "neutral" (i.e., an article's average is within -0.5 to 0.5 on both slant dimensions), $57 \%$ of political articles from these websites are perceived as neutral.

To see what this looks like in practice, this neutral political category includes topical coverage of politics that does not attack the opposition in an uncivil manner. For instance, Huffington Post featured neutral articles such as "North Carolina Republicans Renew Push For Voter ID Requirement" and "Report: FEMA Chief Misused \$150,000, Including Family Trip To Pineapple Farm." And, Fox News' neutral coverage included stories such as "Candidates vying for Corker's Senate seat in Tennessee primary" and "Biden, Sanders viewed as top 2020 contenders among Iowa's Democratic voters: poll." While such articles may be 
used to persuade voters or prime aspects of politics that are favorable for their party, their civil tone and the point-counterpoint article format they use are a clear departure from the more hostile coverage typically associated with such partisan news sources on cable television.

Of course, these partisan online outlets also provide hostile criticism of the other side in the manner that is typically associated with them. Our content analysis reveals some coverage of this type, although we note it is less prevalent than the non-political and neutral political stories previously discussed. In our content analysis, articles from Huffington Post like "Kirsten Gillibrand Slams GOP Senators As Patronizing Bullies For Kav Response" and "Bill Maher Roasts Trump Over His Close Relationship With Sean Hannity" are consistent with the website's reputation. Fox News also provides such coverage, in articles such as "MARC THIESSEN: Obama took lying to new levels in Iran deal" and "Despite carbon footprint, Sanders spent big money flying privately: report." 


\section{B Appendix B: Descriptive Study of Partisan Selective Exposure and Oppositional Media Hostility}

The data for the descriptive analysis was collected in March 2018. The web tracking application had been installed by 1045 survey respondents. We focus on 699 partisan respondents who completed the survey and had at least one visit to Fox News or Huffington Post.

\section{B.1 Descriptive Study Demographics}

Survey respondents were recruited using YouGov's standard procedure in which an initial, unrepresentative sample was matched to a national-representative target distribution. The table below displays the demographics of 1) all those respondents who assessed media outlets in the survey (used to assess perceptions of media outlet bias in the figure below) and 2) all those partisan respondents who visited at least one of Fox News and the Huffington Post in the web tracking data (those in the descriptive analysis that appears in the main text).

Table B1: Descriptive Study Demographics

\begin{tabular}{rrr}
\hline & Survey Sample (Weighted) & Traffic Sample (Unweighted) \\
\hline Black & 0.11 & 0.05 \\
Hispanic & 0.10 & 0.04 \\
White & 0.73 & 0.85 \\
Other Race & 0.06 & 0.06 \\
College Plus & 0.37 & 0.44 \\
Female & 0.55 & 0.53 \\
Income & 4901.46 & 72120.25 \\
Age & 50.94 & 58.16 \\
Democrat & 0.45 & 0.59 \\
Republican & 0.40 & 0.41 \\
Independent & 0.15 & 0.00 \\
\hline Sample Size & 1045 & 699 \\
\hline
\end{tabular}




\section{B.2 Fox News and Huffington Post Reputations}

The figure below uses the full, weighted survey sample discussed above and displays perceptions of partisan slant (measured on a seven-point scale from 1: "Liberal or pro-Democratic party bias" , to 4: "No bias at all", to 7: "Conservative or pro-Republican party bias") for twelve media organizations. Values below four indicate a perception that a news outlet has a left-leaning or pro-Democratic slant. Values above four indicate a perception that a news outlet has a right-leaning or pro-Republican slant. Placements at four indicate an outlet is perceived as not having any partisan or ideological bias.

These comparisons indicate that Fox News and Huffington Post have clear partisan reputations and are at the extremes of these assessments. From this assessment the reputations of these two sources seem to be perceived as ideologically extreme to roughly the same degree by respondents with Huffington Post $(2.5,1.5$ points from the neutral mid-point of the scale) and Fox News (5.7, 1.7 points from the neutral mid-point of the scale) seen as roughly equivalent distances from providing neutral coverage, though in opposing directions. 
Figure B1: Perceived Media Outlet Slant

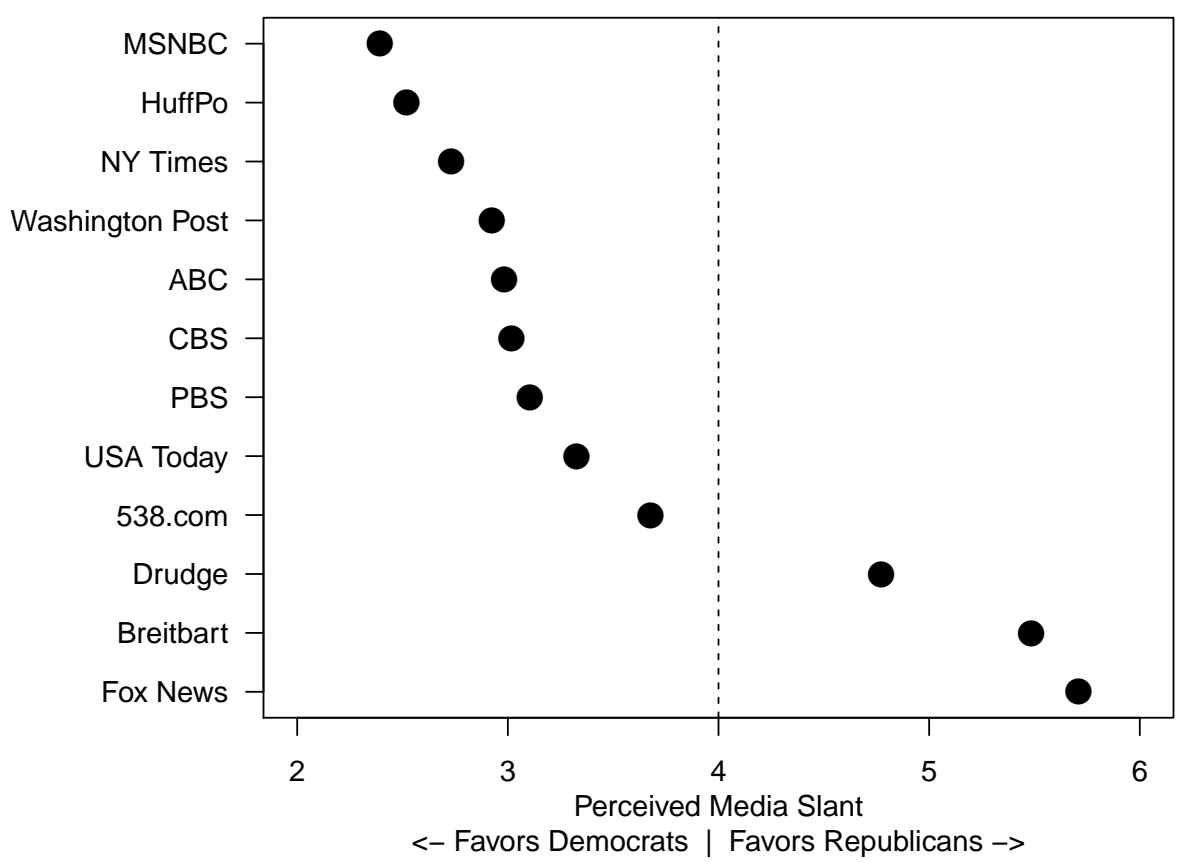

Note: Figure displays the average ideological ratings of various news outlet among all survey respondents in March 2018 ( $\mathrm{n}=1045)$. Results are weighted using sampling weights provided by YouGov.

\section{B.3 Relating News Exposure and Oppositional Media Hostility}

This section considers the relationship between media exposure and the media feeling thermometers. We assess the robustness of the results from Figure 1 of the main text by seperating those with high (more than 99 total visits to the combination of Fox News and Huffington Post) and low levels of political news exposure (those with fewer than 99 total visits to the combination of Fox News and Huffington Post). These results are displayed in Figure B2. This shows these relationships are magnified among the most frequent news consumers, but also generally hold among those with less overall exposure to these two websites. 
Figure B2: Media Outlet Favorability by Use (Fox News and Huffington Post)
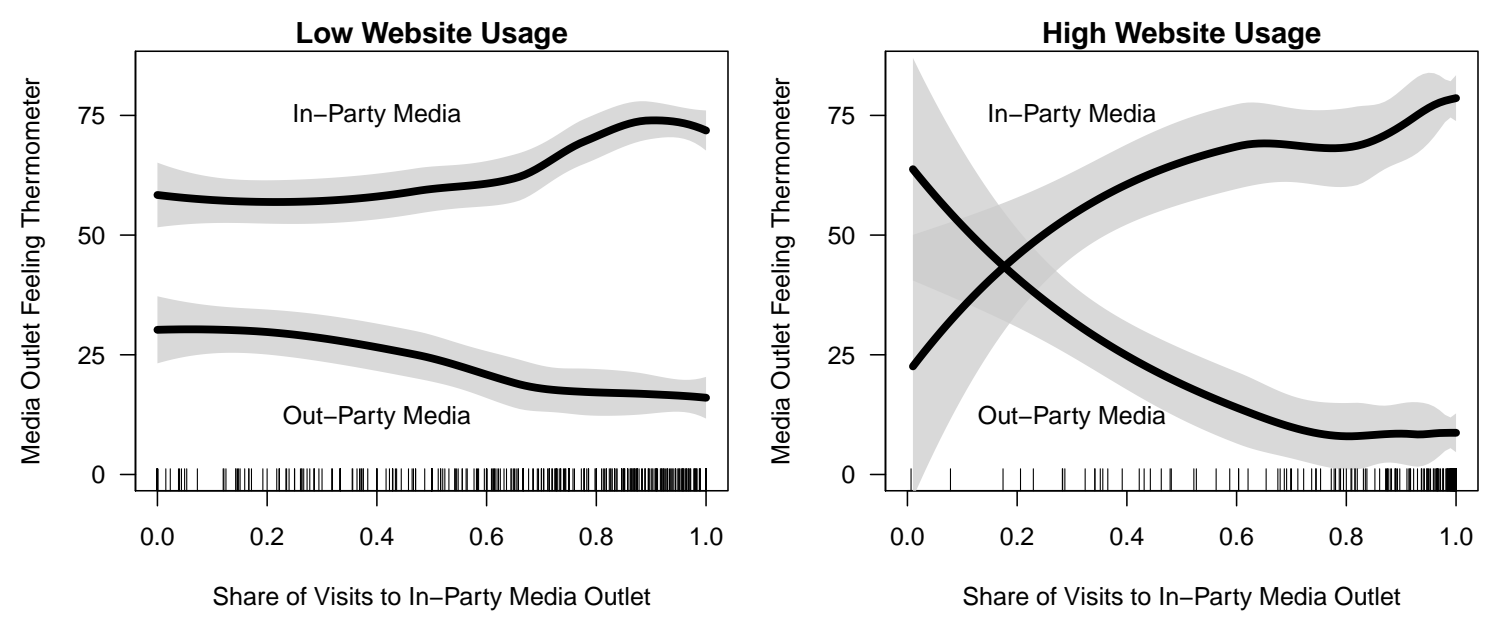

Note: Figure displays predicted values from LOESS regressions of partisan survey respondents' approval of Fox News and Huffington Post on their relative use of the websites. The in-party source for Republicans is Fox News and for Democrats is Huffington Post. In-party visit share is the number of visits to their in-party site divided by their total number of visits to Fox News and Huffington Post. The left panel displays those with 99 or fewer visits to the two websites (i.e., the bottom three quartiles of users), while the right panel considers those with more than 99 visits to the two websites (i.e, the top quartile of users).

We also address the robustness of these relationships by estimating regressions that control for other, potentially confounding variables. Table B2 does this for the difference between in and out-party ratings of these media outlets, an analogue to the common measure of partisan affective polarization. Table B3 examines the in-party media thermometer as the outcome. Table B4 does so using only the out-party media thermometer as the outcome.

In each table the "Bivariate" column displays the results from regressing the outcome on the media exposure variable. The next column does this only for Democrats in the sample. The third column does so only for Republicans in the sample. The fourth column does so only for the the top quartile of the sample in terms of overall number of visits to these sites, the fifth column regresses the outcome on the the media exposure measure and also includes the following covariates: the 7-pt Party ID scale, gender, race, age, income and political interest. 
Across each of these specifications there is a consistent pattern: more one-sided exposure to co-partisan media sources predicts more positive views of the in-party media outlet, more negative views of the out-party media outlet, and a larger gap between these two ratings.

Table B2: DV: In-Party Media Therm - Out-Party Media Therm

\begin{tabular}{lrrrrr}
\hline & Bivariate & Dems Only & Reps Only & High Usage & W/Covariates \\
\hline (Intercept) & $19.70^{*}$ & $33.53^{*}$ & 3.87 & 7.77 & 21.83 \\
& $(3.45)$ & $(4.42)$ & $(5.35)$ & $(8.58)$ & $(25.71)$ \\
In Party Source Share & $42.60^{*}$ & $27.76^{*}$ & $59.51^{*}$ & $63.68^{*}$ & $26.95^{*}$ \\
& $(4.33)$ & $(5.46)$ & $(6.90)$ & $(9.65)$ & $(4.09)$ \\
\hline$N$ & 699 & 415 & 284 & 204 & 699 \\
\hline
\end{tabular}

Standard errors in parentheses

${ }^{*}$ indicates significance at $p<0.05$

Table B3: DV: In-Party Media Therm

\begin{tabular}{lrrrrr}
\hline & Bivariate & Dems Only & Reps Only & High Usage & W/Covariates \\
\hline (Intercept) & $52.75^{*}$ & $57.55^{*}$ & $46.65^{*}$ & $45.07^{*}$ & 33.39 \\
& $(2.30)$ & $(2.83)$ & $(3.65)$ & $(6.05)$ & $(17.92)$ \\
In Party Source Share & $21.85^{*}$ & $11.81^{*}$ & $36.16^{*}$ & $33.33^{*}$ & $15.96^{*}$ \\
& $(2.89)$ & $(3.50)$ & $(4.70)$ & $(6.80)$ & $(2.85)$ \\
\hline$N$ & 699 & 415 & 284 & 204 & 699 \\
\hline
\end{tabular}

Standard errors in parentheses

* indicates significance at $p<0.05$

Table B4: DV: Out-Party Media Therm

\begin{tabular}{lrrrrr}
\hline & Bivariate & Dems Only & Reps Only & High Usage & W/Covariates \\
\hline (Intercept) & $33.04^{*}$ & $24.02^{*}$ & $42.78^{*}$ & $37.30^{*}$ & 11.55 \\
& $(2.30)$ & $(2.86)$ & $(3.47)$ & $(5.19)$ & $(17.07)$ \\
In Party Source Share & $-20.75^{*}$ & $-15.95^{*}$ & $-23.34^{*}$ & $-30.34^{*}$ & $-11.00^{*}$ \\
& $(2.88)$ & $(3.53)$ & $(4.47)$ & $(5.84)$ & $(2.71)$ \\
\hline$N$ & 699 & 415 & 284 & 204 & 699 \\
\hline
\end{tabular}

Standard errors in parentheses

* indicates significance at $p<0.05$

These descriptive analyses motivate our three experiments by showing an association between 
selective exposure and negative views of out-party media and, conversely, between crosscutting exposure and positive views of out-party media.

\section{B.4 Predicting Selective Exposure}

In this section we consider variables that predict one-sided news exposure to these websites. In line with previous research on partisan selective exposure (e.g., Stroud 2010, Levendusky 2013a) we expect that those with stronger partisan attachments and higher levels of political interest to have more one-sided patterns of news exposure to the partisan sources we consider.

We operationalize this by regressing a respondent's share of visits to their in party news source, our key independent variable in the preceding analysis, on whether or not they are a strong partisan and whether or not they have a high level of political interest. The results are displayed below in Table B5.

Table B5: Predicting In Party Source Share

\begin{tabular}{lr}
\hline & In Party Source Share \\
\hline (Intercept) & $0.51^{*}$ \\
& $(0.04)$ \\
Strong Partisan & $0.08^{*}$ \\
& $(0.02)$ \\
High Political Interest & $0.19^{*}$ \\
& $(0.04)$ \\
\hline$N$ & 699 \\
\hline Standard errors in parentheses \\
$*$ indicates significance at $p<0.05$
\end{tabular}

We find both partisan strength and political interest are correlated with more partisan selectivity, both producing statistically significant increases of in party source share. This motivates our use of survey experiments, which allow us to randomly assign news exposure that would not occur if respondents actively chose the news they wished to encounter. 


\section{Appendix C: Additional Material for Experiment 1}

\section{C.1 Experiment 1 Demographics}

Table C1 displays demographics of partisan respondents in Experiment 1. This sample was from a Survey Sampling International panel. It included "pure" independents, but we exclude them for our analysis as we cannot determine cross-cutting exposure for this group.

Table C1: Experiment 1 Demographics

\begin{tabular}{rr}
\hline & Experiment 1 \\
\hline Black & 0.13 \\
Hispanic & 0.13 \\
White & 0.66 \\
Other Race & 0.08 \\
College Plus & 0.33 \\
Female & 0.51 \\
Age & 44.85 \\
Democrat & 0.57 \\
Republican & 0.43 \\
\hline Sample Size & 1879 \\
\hline
\end{tabular}

\section{C.2 Experiment 1 Article Selection}

Non-political articles were selected by reading coverage from a variety of news sources prior to fielding the survey. These headlines, their category and source, are displayed in Table C2.

Table C2: Non-Political Articles in Experiment 1

\begin{tabular}{lll}
\hline Headline & Category & Appeared On \\
\hline Female film protagonists reached all-time high in 2016 & Arts and Culture & CNN \\
Hewlett Packard Earnings: What's Up for Q1 Earnings? & Business & Yahoo Finance \\
Are You a Netflix Cheater? & Entertainment & CNN \\
Acupuncture Shows Promise In Migraine Treatment, Study Says & Health and Wellness & CNN \\
Roaming telescope brings Kenyan kids views of night sky & Science & Yahoo News \\
Lakers put Magic Johnson in Charge of Basketball Ops & Sports & Fox News \\
Kendall Jenner, Bella Hadid and Winnie Harlow Party With Love Magazine & Style & New York Times \\
Everything we know about the next iPhone so far & Tech & Yahoo News \\
America's most popular national parks are ... & Travel & Fox News \\
\hline
\end{tabular}


The process for selecting political articles was more involved to ensure articles fit the appropriate category in terms of their partisan valence. Coders on Amazon's Mechanical Turk were asked to rate headlines drawn from Huffington Post (10 headlines), Fox News (10 headlines) and the Associated Press (20 headlines) using the following question "Is this headline positive, neutral, or negative towards members of the [Democratic/Republican] party?" These headlines were selected by searching for headlines mentioning the opposing political party on Huffington Post and Fox News and collecting a set of political stories from the AP Newswire.

We focus on these headline ratings as this was the material available to respondents when they were selecting whether or not to read the article. To improve the quality of these ratings, there were several qualifications required for Mturk workers to qualify for this task. First, they needed to complete a short 3-item political knowledge test. Second, they needed to have a $95 \%$ approval rating on their prior HITs. Third, they needed to have completed at least 500 total HITs. This follows best practices to ensure quality ratings that have been previously employed when crowdsourcing measures of media bias (e.g., Budak et al. 2016).

Each headline received 50 ratings. Respondents separately rated each headline's slant towards Republicans and Democrats with a 5-point scale where negative numbers indicate a headline is very $(-2)$ or somewhat $(-1)$ negative towards a partisan group, positive ratings indicate a headline is very (2) or somewhat (1) favorable towards a partisan group and ratings of zero indicate a headline is neutral towards a partisan group.

With the goal of creating a set of clearly partisan and clearly neutral stories we removed headlines that received mixed ratings from coders to produce a final set of 17 headlines matching the needs of each treatment group. Respondents were then randomly assigned one of the stories in the appropriate category when taking the survey. 
TableC3 displays these headlines, their category, the average slant rating they received across the 50 coders and the inter-coder agreement for placing a headline in its category. Agreement occurred when a coder gave the headline a negative rating towards the relevant party for the "Partisan-HuffPo" or "Partisan-Fox" categories and a rating between -1 (somewhat negative) and 1 (somewhat positive) towards both parties for the "Neutral" category.

Table C3: Political Headline Ratings by Treatment Category (Experiment 1)

\begin{tabular}{|c|c|c|c|c|c|}
\hline & Headline & Category & Dem-Slant & Rep-Slant & \% Agreement \\
\hline 1 & Trump's speech to Congress: 'Time for small thinking over' & Neutral & -0.18 & 0.34 & 90 \\
\hline 2 & Trump Set to Roll Back Federal Fuel-Economy Requirements & Neutral & -0.06 & 0.10 & 100 \\
\hline 3 & Republican Members of Congress face Trump foes at Town Halls & Neutral & -0.02 & -0.28 & 100 \\
\hline 4 & Forget about insurance coverage; new Republican buzzwords in Washington are health care access & Neutral & -0.02 & -0.22 & 96 \\
\hline 5 & Doctor-turned-pundit with conservative views is Trump's pick to lead Food and Drug Administration & Neutral & -0.02 & -0.10 & 94 \\
\hline 6 & Democratic former state senator weighs run for Wisconsin governor & Neutral & 0.32 & -0.04 & 100 \\
\hline 7 & Democrats Keep Showing Off Their Civic Ignorance & Fox-Partisan & -1.64 & 0.04 & 92 \\
\hline 8 & Disgraceful: Top Dems Couldn't Put Politics Aside, Remained Seated When Navy SEAL's Widow Was Honored & Fox-Partisan & -1.62 & 0.22 & 88 \\
\hline 9 & 'It's Disgusting': Judge Jeanine Says Dems 'Will Use Anything' They Can Against Trump & Fox-Partisan & -1.50 & 0.34 & 90 \\
\hline 10 & Meet the Democrats Who Don't Dare Face Voters at Town Halls & Fox-Partisan & -1.44 & 0.06 & 96 \\
\hline 11 & Amazon best-seller 'Reasons to Vote for Democrats' book is just empty pages & Fox-Partisan & -1.44 & 0.16 & 90 \\
\hline 12 & President Trump's VOICE Is About Justifying White Supremacy & HuffPo-Partisan & 0.06 & -1.60 & 90 \\
\hline 13 & Republican Pick-Up Lines Are About As Creepy As You Might Imagine & HuffPo-Partisan & 0.06 & -1.58 & 96 \\
\hline 14 & Before Meeting With Muslim Constituents, Republican Lawmaker Asks If They Beat Their Wives & HuffPo-Partisan & 0.08 & -1.62 & 96 \\
\hline 15 & Bill Maher Shreds Republicans For 'Letting Trump Run Down America' & HuffPo-Partisan & 0.14 & -1.58 & 94 \\
\hline 16 & What Are You, A Sociopath? The Lack Of A Conscience In The Republican Agenda & HuffPo-Partisan & 0.16 & -1.72 & 96 \\
\hline 17 & World's Saddest Trump Rally Draws Just 8 Supporters & HuffPo-Partisan & 0.18 & -1.42 & 90 \\
\hline
\end{tabular}

Overall, "neutral" headlines received ratings close to zero and few coders saw them as positive or negative towards one of the parties. Headlines in the "Fox-Partisan" category received a very negative average rating towards Democrats and a higher percentage of the raters agreed that the headlines portrayed the Democrats negatively. Headlines in the "Anti-Rep" category received a very negative rating towards Republicans and again a high percentage of coders agreed the ratings portrayed Republicans negatively.

Figure C1 below shows these measures of slant for each headline and indicates there is a clear distinction between the headlines placed in different treatement categories for the experiment. 
Figure C1: Perceived Slant by Headline Category (Experiment 1)

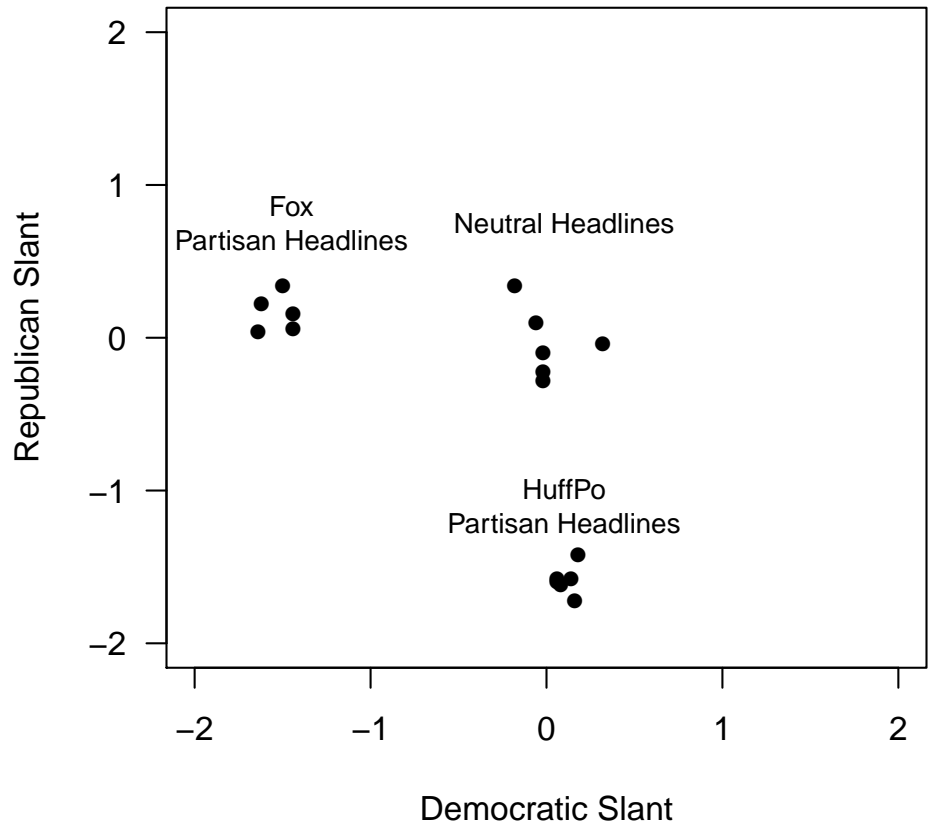

Note: Figure displays each headline's mean slant rating towards the Democratic and Republican parties across ratings offered by 50 coders on Amazon's Mechanical Turk.

After respondents were assigned to a particular political news coverage category, they were randomly assigned one of the headlines from the appropriate category. As we discuss in the main text, this aids the generalizability of the experimental treatments in this study. Our results do not hinge on one particular type of political news coverage story in each category, helping to address concerns that would otherwise arise about the potentially idiosyncratic nature of the headline used to represent a broader theoretical category of news coverage.

\section{C.3 Supplementary Analysis: Pooling In-Party and Out-Party Conditions}

In Table C4 we pool together the two in-party and two out-party exposure conditions presented in Table 2 of the main text. We do this to provide comparison between the overall effects of out-party and in-party media exposure which are discussed in the main text. 
Table C4: Media Outlet Thermometer Ratings by Exposure

\begin{tabular}{lccc}
\hline & In-Party Media & Out-Party Media & In-Party - Out-Party \\
\hline (Intercept) & $62.67^{*}$ & $37.33^{*}$ & $25.33^{*}$ \\
& $(1.31)$ & $(1.72)$ & $(2.01)$ \\
Out-Party Exposure & 0.22 & $8.64^{*}$ & $-8.43^{*}$ \\
& $(1.51)$ & $(1.98)$ & $(2.33)$ \\
In-Party Exposure & $4.10^{*}$ & 3.26 & 0.84 \\
& $(1.49)$ & $(1.96)$ & $(2.30)$ \\
\hline$N$ & 1879 & 1879 & 1879 \\
\hline
\end{tabular}

Reference category is no news exposure

Models control for party

Standard errors in parentheses

* indicates significance at $p<0.05$

\section{C.4 Supplementary Analysis: News Choice as Outcome}

The two-stage process of Experiment 1 also provides an outcome variable beyond perceptions of various media outlets. After they saw the initial article, respondents were able to select a second news story to read from the news outlet they reached and could choose between a political story (randomly assigned to be neutral or consistent with the source's reputation) or another non-political piece of coverage (randomly assigned from the non-political categories they had not already seen). Below we consider the effects of the type of political article that was made available to them on their news choices for the second article. 
Table C5: $\operatorname{Pr}($ Select Political Story) By Source and Article Content in Experiment 1

\begin{tabular}{lrr}
\hline & Overall & By Political Content Type \\
\hline (Intercept) & 0.50 & 0.50 \\
& $(0.35)$ & $(0.36)$ \\
Out-Party Source & $-0.08^{*}$ & -0.00 \\
& $(0.03)$ & $(0.04)$ \\
Partisan Article & & 0.04 \\
& & $(0.03)$ \\
Out-Party Source $\times$ Partisan Article & $-0.15^{*}$ \\
& & $(0.05)$ \\
\hline$N$ & 1508 & 1508 \\
\hline Robust standard errors in parentheses & \\
$*$ indicates significance at $p<0.05$ & & \\
Models control for respondent partisanship, news website and the type of non-political alternative
\end{tabular}

The first column shows that respondents were less likely to select a political article when assigned to an out-party source relative to when they reached an in-party source. The second column shows this is concentrated among those who saw partisan news articles. The interaction between out-party source and partisan article is large indicating that respondents were particularly deterred from selecting highly-partisan articles when on an out-party website. In contrast, there is no detectable difference in their likelihood of selecting the neutral political articles based on whether they were assigned to an in-party or out-party news source.

We also consider the variables that predict avoidance of the out-party hostile political content in Table C5. Among those in the out-party conditions, we regress their choice of the political story on whether or not they were a strong partisan and had a high degree of political interest. We separately consider the neutral political coverage from an out-party source (Column 1) and those considering the hostile political coverage from an out-party source (Column 2). 
Table C6: $\operatorname{Pr}$ (Select Out-Party Political Story) By Article Content in Experiment 1

\begin{tabular}{lcc}
\hline & Chose Out-Party Neutral Political & Chose Out-Party Hostile Political \\
\hline (Intercept) & $0.48^{*}$ & $0.41^{*}$ \\
& $(0.06)$ & $(0.06)$ \\
Strong Partisan & 0.05 & 0.02 \\
& $(0.05)$ & $(0.05)$ \\
High Political Interest & 0.09 & 0.04 \\
& $(0.06)$ & $(0.06)$ \\
\hline$N$ & 344 & 369 \\
\hline
\end{tabular}

Robust standard errors in parentheses

* indicates significance at $p<0.05$

While these covariates do not reach statistical significance, it is notable that the strong partisanship is more predictive of selecting the neutral content from the out-party than it is for selecting the hostile content from the out-party. Likewise, political interest is more predictive of selecting the neutral political coverage than it is of selecting the hostile coverage.

In tandem, these patterns help explain the null findings in the main text, where seeing a partisan headline did not shift views of the out-party source relative to encountering a neutral political article. Consistent with previous work (Arceneaux and Johnson 2013), this indicates respondents avoided hostile political coverage, with suggestive indications this was strongest among the types of individuals who may have responded more negative to these forms of out-party coverage. This potentially insulated them from the negative effects encountering this coverage would have on their out-party outlet assessments. 


\section{Appendix D: Additional Material for Experiments}

\section{2 and 3}

\section{D.1 Experiments 2 and 3 Article Selection}

For the second and third experiments we used a similar procedure as the first experiment to determine the news coverage to display. However, there was one key modification. In these studies all of the news coverage respondents encountered had originally appeared on the news outlet to which it was attributed, this ensures we capture any ways in which a website's partisan leanings intrude into its non-political and ostensibly neutral coverage of politics (e.g., perhaps by emphasizing certain topics over others).

Based on this requirement, we determined non-political articles that appeared on Fox News and the Huffington Post. The headlines of these non-political articles are displayed below.

Table D1: Non-Political Articles in Experiments 2 and 3

\begin{tabular}{ll}
\hline Headline & Category \\
\hline Italian church, cops dupe art thieves by swapping out original \$3M masterpiece for fake & Arts and Culture \\
Top Movies And TV Shows Lack Characters With Mental Health Conditions & Arts and Culture \\
Costco sells $\$ 7$ B in clothing a year, surpassing some apparel retailers & Business \\
Google Investing $\$ 1$ Billion To Fix Bay Area's Tech-Driven Housing Crisis & Business \\
Netflix will curb smoking in original programming following complaints about 'Stranger Things' & Entertainment \\
'Stranger Things' Report Prompts Netflix To Cut Back On-Screen Smoking & Entertainment \\
New study suggests that certain diets lower risk of death from breast cancer & Health and Wellness Fox News \\
Burnout Is Now A Legitimate Diagnosis, Says World Health Organization & Health and Wellness Huffington Post \\
Saturn's moon Enceladus could support life as more evidence emerges & Science \\
Now Wasps Are Forming Massive 'Super Nests' Because Life Just Isn't Scary Enough & Science \\
Tiger Woods no longer target of wrongful-death suit & Sports \\
Ex-Olympics Official Got $\$ 2.4$ Million In Severance After Larry Nassar Cover-Up & Sports \\
Don't expect 'Friends' star Jennifer Aniston to ever change her signature hair color & Style \\
Mindy Kaling Told Us Her Secret To Stunning Skin On Less Sleep & Style \\
Domino's pizza pie to be delivered using robotic vehicle & Tech \\
Facebook Goes Back To Its Roots With Dating App Feature & Tech \\
TSA reports that nearly $\$ 1$ million was left in US airports in 2018 & Travel News \\
Hero 4-Year-Old Tells Air Passenger Where To Stick Her Stinky Bare Foot & Huffington Post \\
\hline
\end{tabular}

When determining political articles, we used the same crowd-sourcing procedure as the first experiment, this time with the added need to determine neutral political coverage that appeared on Fox News and Huffington Post. From an initial 67 candidate political headlines, 
we selected 41 in the table below to use based on their clear alignment with the requirements

for a category (i.e., either perceived as neutral or partisan in the intended manner).

Table D2: Political Headline Ratings by Treatment Category (Experiments 2 and 3)

\begin{tabular}{|c|c|c|c|c|c|}
\hline & Headline & Category & Dem-Slant & Rep-Slant & \% Agreement \\
\hline 1 & Florida Dem admits lying about treating Pulse shooting victims: 'I just made it up' & Fox-Partisan & -1.78 & 0.06 & 96.00 \\
\hline 2 & Ingraham: California a 'Democrat-induced disaster' & Fox-Partisan & -1.60 & 0.02 & 88.00 \\
\hline 3 & Rush Limbaugh: 'The left is totally crazy,' Democratic Party will 'fall apart' if Biden nominated & Fox-Partisan & -1.54 & 0.00 & 90.00 \\
\hline 4 & Rep. Cheney: Dems' actions 'really shameful' & Fox-Partisan & -1.50 & 0.14 & 92.00 \\
\hline 5 & Nikki Haley slams 'disgusting' silence from Dems after Mexican flag raised at ICE facility & Fox-Partisan & -1.42 & 0.12 & 86.00 \\
\hline 6 & Hannity: Dems abusing their power, guilty of 'presidential harassment' & Fox-Partisan & -1.40 & 0.06 & 88.00 \\
\hline 7 & Trump 2020 press secretary: 'Time after time we see these anti-American remarks' from Democrat 'squad' & Fox-Partisan & -1.38 & 0.12 & 88.00 \\
\hline 8 & Ingraham: 'Left' trying to destroy what it means to be American & Fox-Partisan & -1.36 & 0.10 & 84.00 \\
\hline 9 & Hannity: 'All-out war' going on within the Democratic Party & Fox-Partisan & -1.34 & -0.08 & 88.00 \\
\hline 10 & Dem socialist Julia Salazar allegedly dipped into trust fund during state senate campaign: report & Fox-Partisan & -1.28 & 0.00 & 90.00 \\
\hline 11 & Former ICE director: Dems 'drive' to see Trump fail more important to them than immigrant lives & Fox-Partisan & -1.26 & -0.06 & 82.00 \\
\hline 12 & Conway blasts Dems' 'tired' claims of racism, says she 'totally disagrees' with husband's scathing op-ed & Fox-Partisan & -1.24 & -0.02 & 86.00 \\
\hline 13 & Collins slams Pelosi for Trump remark: Dems have run roughshod over House institutions & Fox-Partisan & -1.18 & 0.06 & 86.00 \\
\hline 14 & Hannity: 'Deep wounds' divide the Democrats & Fox-Partisan & -1.14 & 0.00 & 92.00 \\
\hline 15 & Republican Compared Anti-LGBTQ Proposal To Saving Jews From Holocaust & HuffPo-Partisan & 0.00 & -1.32 & 82.00 \\
\hline 16 & Donald Trump Calls Lawmakers 'Racist' After His Own Racist Attacks On Them & HuffPo-Partisan & 0.00 & -1.26 & 80.00 \\
\hline 17 & For 3 Years, This Husband Has Fought For His Wife. Trumps Muslim Ban Keeps Them Apart. & HuffPo-Partisan & 0.00 & -1.24 & 84.00 \\
\hline 18 & Texas Republican Says Women Should 'Absolutely' Be Jailed For Having An Abortion & HuffPo-Partisan & 0.02 & -1.16 & 80.00 \\
\hline 19 & Trump Lies About Congresswomen Of Color Referring To 'Evil Jews' & HuffPo-Partisan & 0.06 & -1.36 & 82.00 \\
\hline 20 & Donald Trump Resurrects Lie That China Is Paying His Tariffs & HuffPo-Partisan & 0.08 & -1.10 & 82.00 \\
\hline 21 & Republicans Silent On Trump's Racist Remarks To Congresswomen & HuffPo-Partisan & 0.10 & -1.56 & 98.00 \\
\hline 22 & Asylum Officers Slam Trumps Border Policies As Contrary To America's Moral Fabric & HuffPo-Partisan & 0.16 & -1.28 & 84.00 \\
\hline 23 & Trump's Record Of Ethically Tainted Cabinet Departures Rises With Acosta's Exit & HuffPo-Partisan & 0.16 & -1.22 & 82.00 \\
\hline 24 & Major European Business Leader Slams Trump For Promoting 'Racism And Exclusion' & HuffPo-Partisan & 0.18 & -1.32 & 82.00 \\
\hline 25 & Dalai Lama Says Donald Trump Lacks 'Moral Principle' & HuffPo-Partisan & 0.18 & -1.26 & 86.00 \\
\hline 26 & Trump tells Congress to immediately approve Mexico-Canada trade deal, says US moving past stupid years of trade policy & Fox-Neutral & -0.06 & 0.10 & 84.00 \\
\hline 27 & California becomes 1st state to give taxpayer-funded health benefits to illegal immigrants & Fox-Neutral & -0.04 & -0.02 & 80.00 \\
\hline 28 & Sasse leads fresh calls to use seized 'El Chapo' money to pay for border security & Fox-Neutral & 0.00 & 0.18 & 92.00 \\
\hline 29 & GOP rep unveils bill to implement DNA testing at border, as officials warn of child recycling & Fox-Neutral & 0.02 & -0.30 & 90.00 \\
\hline 30 & DOJ announces release of 3,100 inmates as part of criminal reform push & Fox-Neutral & 0.06 & 0.06 & 92.00 \\
\hline 31 & Border apprehensions decline 28 percent following US-Mexico partnership, DHS says & Fox-Neutral & 0.06 & 0.18 & 92.00 \\
\hline 32 & Rep. Will Hurd says Texas Republicans need to do more to diversify their ranks & Fox-Neutral & 0.08 & -0.44 & 88.00 \\
\hline 33 & We Still Don’t Know How Many People Died In American Jails 4 Years Ago & Huffpo-Neutral & -0.06 & -0.04 & 96.00 \\
\hline 34 & Chili Beef Heats Up Between Governors Of Colorado, New Mexico & Huffpo-Neutral & -0.02 & -0.02 & 98.00 \\
\hline 35 & Trump Responds To UK Ambassador Kim Darroch's Resignation & Huffpo-Neutral & -0.02 & 0.14 & 86.00 \\
\hline 36 & Chicago Mayor Permanently Bans ICE From Accessing Police Databases Ahead Of Raids & Huffpo-Neutral & 0.02 & -0.06 & 88.00 \\
\hline 37 & House Panel Accuses Juul Of Directly Targeting Kids At School And Summer Camp & Huffpo-Neutral & 0.04 & -0.04 & 96.00 \\
\hline 38 & Treasury Watchdog Will Look Into The Delay On The Harriet Tubman $\$ 20$ Bill & Huffpo-Neutral & 0.06 & -0.10 & 92.00 \\
\hline 39 & California Passes Measure Requiring Presidential Candidates To Release Tax Returns & Huffpo-Neutral & 0.16 & -0.14 & 88.00 \\
\hline 40 & Cory Booker Wants Prisoners' Sentences To Get Second Look After 10 Years & Huffpo-Neutral & 0.22 & -0.04 & 98.00 \\
\hline 41 & Oregon Just Passed The Best Family Leave Law In The U.S. & Huffpo-Neutral & 0.32 & -0.06 & 92.00 \\
\hline
\end{tabular}

Figure D1 displays the slant ratings these headlines received and also indicates the source they originally appeared on. This indicates there is a clear divide between the groups of headlines we assign respondents to the in second and third experiments. 
Figure D1: Perceived Slant by Headline Category (Experiments 2 and 3)

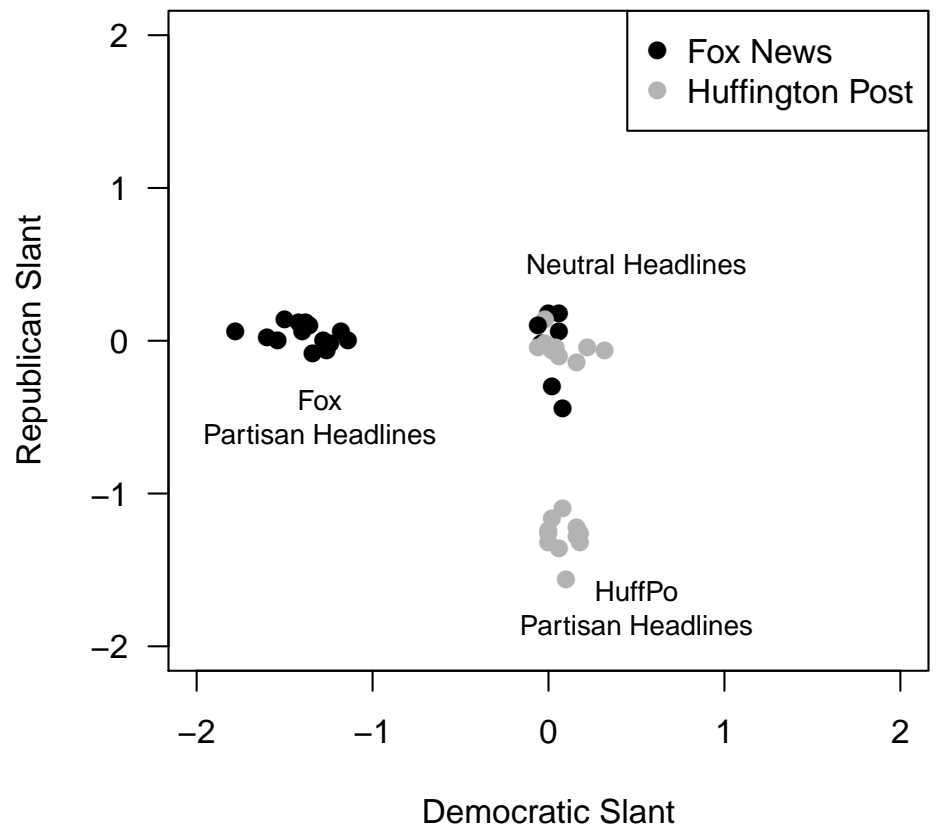

Note: Figure displays each headline's mean slant rating towards the Democratic and Republican parties across ratings offered by 50 coders on Amazon's Mechanical Turk.

\section{D.2 Experiment 2: Additional Material}

\section{D.2.1 Experiment 2 Demographics}

Table D3 displays the demographics of partisan respondents examined in the analysis of Experiment 2 in the main text. This sample was drawn from a panel maintained by Lucid. The sample also included "pure" independents, but we exclude them for our analysis as we do not have an ability to determine what cross-cutting exposure consists of for this group. 
Table D3: Experiment 2 Demographics

\begin{tabular}{rr}
\hline & Experiment 2 \\
\hline Black & 0.11 \\
Hispanic & 0.07 \\
White & 0.70 \\
Other Race & 0.13 \\
College Plus & 0.41 \\
Female & 0.51 \\
Age & 45.48 \\
Income $(\$)$ & 55338.94 \\
Democrat & 0.54 \\
Republican & 0.46 \\
\hline Sample Size & 4250 \\
\hline
\end{tabular}

\section{D.2.2 Supplementary Analysis: Consistent Partisans Only}

For $95 \%$ of respondents, the partisanship available from the panel information provided by Lucid, the measure of partisanship that was used to assign them to out-party media exposure conditions, agreed with the partisanship they indicated in questions asked at the end of our survey. Because there is some discrepancy between these two measures, our primary analysis incorrectly assigns some individuals for the purposes of understanding their views of out-party media sources. For this reason we reassess our findings in this experiment after dropping individuals with inconsistent measures of partisanship between the panel measure and the post-treatment measure in our survey. These findings are shown in Table D4. 
Table D4: Out-Party Media Ratings by Exposure Condition (Consistent Partisanship Only)

\begin{tabular}{|c|c|c|}
\hline & Out-Party Media & Media Difference \\
\hline \multirow[t]{2}{*}{ (Intercept) } & $13.10^{*}$ & $53.79^{*}$ \\
\hline & $(0.98)$ & $(1.35)$ \\
\hline \multirow[t]{2}{*}{ Hostile Out-Party } & -1.02 & 0.54 \\
\hline & $(1.05)$ & $(1.43)$ \\
\hline \multirow[t]{2}{*}{ Neutral Out-Party } & $3.34^{*}$ & -2.25 \\
\hline & $(1.06)$ & $(1.44)$ \\
\hline \multirow[t]{2}{*}{ Non-Political Out-Party } & $4.63^{*}$ & $-3.32^{*}$ \\
\hline & $(1.04)$ & $(1.43)$ \\
\hline$N$ & 4075 & 4075 \\
\hline \multicolumn{3}{|c|}{ Reference category is no news exposure } \\
\hline \multirow{2}{*}{\multicolumn{3}{|c|}{ Models control for party and pre-treatment views of out-party media bias }} \\
\hline \multicolumn{2}{|c|}{ Standard errors in parentheses } & \\
\hline \multicolumn{3}{|c|}{${ }^{*}$ indicates significance at $p<0.05$} \\
\hline
\end{tabular}

This shows we obtain similar evidence after removing those individuals with inconsistent measures of partisanship between the panel data and the survey.

\section{D.2.3 Supplementary Analysis: Differences in Perceived Content (Pairwise Tests of Differences)}

In Table 4 in the main text we show the perceived likelihood that various types of coverage appeared on a website to capture public perceptions of these sources. In Table D5 and Table D6 we formally test the pairwise difference in the perceived likelihood of appearance between each pair of coverage types and present a associated p-value for the statistical significance of the difference. We place the key comparisons between the perceived likelihood of hostile coverage attacking the out-party and neutral or non-political coverage in bold in each table. 
Table D5: Difference in Perceived Likelihood Coverage Appeared on Huffington Post

\begin{tabular}{rrr}
\hline & Difference & P-Value \\
\hline Hostile to Dems - Neutral & -0.31 & 0.00 \\
Hostile to Reps - Neutral & 0.33 & 0.00 \\
Non-Political - Neutral & -0.40 & 0.00 \\
Hostile to Dems - Non-Political & 0.09 & 0.19 \\
Hostile to Reps - Non-Political & 0.72 & 0.00 \\
Hostile to Reps - Hostile to Dems & 0.64 & 0.00 \\
\hline
\end{tabular}

Table D6: Difference in Perceived Likelihood Coverage Appeared on Fox News

\begin{tabular}{rrr}
\hline & Difference & P-Value \\
\hline Hostile to Dems - Neutral & 0.53 & 0.00 \\
Hostile to Reps - Neutral & -0.16 & 0.02 \\
Non-Political - Neutral & -0.52 & 0.00 \\
Hostile to Dems - Non-Political & 1.04 & 0.00 \\
Hostile to Reps - Non-Political & 0.36 & 0.00 \\
Hostile to Reps - Hostile to Dems & -0.68 & 0.00 \\
\hline
\end{tabular}

The results support the claims in the main text in that the counter-reputational coverage used in our experiments, and commonly available from these sources online, is perceived as much less likely to appear on them than reputationally-consistent coverage that attacks the other party. We have placed these key comparisons in bold. All of the differences between categories are statistically significant with the lone exception that, for the Huffington Post, respondents perceived the non-political and political coverage hostile to Democrats as equivalently likely to appear on the website.

\section{D.2.4 Supplementary Analysis: Reputations Among Out-Partisans Only}

The analysis in the main text considers headline perceptions among all respondents in the control group. Here we subset to only individuals evaluating an out-party news sources and find a similar pattern, with this group considering hostile coverage attacking the out-party as the most likely type of news to appear on these websites. These results are below. 
Table D7: Perceived Likelihood Headline Type Appears on Website (Out-Partisans Only)

\begin{tabular}{r|ll} 
& Fox News & Huffington Post \\
\hline Most Likely (1) & Hostile Towards Democrats (4.0) & Hostile Towards Republicans (3.6) \\
$(2)$ & Neutral Political (3.3) & Neutral Political (3.3) \\
$(3)$ & Hostile Towards Republicans (3.2) & Non-Political (2.9) \\
Least Likely (4) & Non-Political (2.8) & Hostile Towards Democrats (2.8)
\end{tabular}

Note: Table displays the perceived likelihood, measured on a five-point scale, that various types of headlines appear on a website from control group respondents evaluating an out-party source in Study 2 ( $\mathrm{n}=540)$.

\section{D.3 Experiment 3: Additional Material}

\section{D.3.1 Experiment 3 Demographics}

Table D8 displays the demographics of partisan respondents examined in Experiment 3. This is a convenience sample from Amazon's Mechanical Turk. The sample included "pure" independents, but we exclude them for our analysis as we do not have an ability to determine cross-cutting exposure for this group.

Table D8: Experiment 3 Demographics

\begin{tabular}{rr}
\hline & Experiment 3 \\
\hline Black & 0.09 \\
Hispanic & 0.05 \\
White & 0.69 \\
Other Race & 0.17 \\
College & 0.58 \\
Female & 0.49 \\
Democrat & 0.63 \\
Republican & 0.37 \\
\hline Sample Size & 2263 \\
\hline
\end{tabular}

\section{D.3.2 Additional Outcome Measures}

The third experiment included several survey questions about a respondent's evaluations of out-party media used to create a scale. This scale includes the feeling thermometer. It also 
includes one item with a four-point scale that asked respondents whether the out-party outlet dealt fairly with all sides, a second item with a seven-point scale that asked respondents whether the out-party outlet provided accurate information, and a third item that asked whether the out-party source had an ideological bias on a three-point scale (this was asked in a slightly different format then the pre-treatment question).

We combine these items into a single outcome measure by centering and re-scaling the four survey items, conducting principal components analysis on them and extracting the first principal component, which accounts for $68 \%$ of the variation in these assessments of outparty media sources. Based on the item loadings, indicated in the table below, positive values indicate more favorable views of the out-party media. We scale this outcome to have mean zero and standard deviation one. This approach helps reduce any measurement error present when using individual survey items and considers a broader range of outcomes which should also be moved by cross-cutting exposure.

Table D9: Out-Party Media Assessment - PCA Loadings

\begin{tabular}{ll}
\hline Survey Item & PC1 Loading \\
\hline Out-Party Media Thermometer (101-pt scale) & 0.55 \\
Out-Party Media Fairness (4-pt scale) & 0.54 \\
Out-Party Media Accuracy (7-pt scale) & 0.55 \\
Out-Party Media Unbiased (3-pt scale) & 0.34 \\
\hline
\end{tabular}




\section{E Appendix E: Pooled Analysis of Experiments}

While they differ, there are shared features across our three experiments. Here we pool together common arms included in different studies. We also examine heterogeneity in these effects by separately analyzing results for Democrats and Republicans.

\section{E.1 Pooled Effects of Non-Political Exposure}

Conditions examining non-political exposure, relative to no news exposure, are included in the first and second experiments. Table E1 pools these results together. We find a pattern similar to the analysis of the individual experiments in the main text, with exposure to non-political coverage from out-party media sources improving views of these outlets and reducing the divide between assessments of in-party and out-party media sources.

Table E1: Pooled Effects of Non-Political Exposure on Views of Out-Party Media (Experiments 1 and 2)

\begin{tabular}{|c|c|c|}
\hline & Out-Party Media & Media Difference \\
\hline \multirow[t]{2}{*}{ (Intercept) } & $44.46^{*}$ & $21.23^{*}$ \\
\hline & $(1.37)$ & $(1.68)$ \\
\hline \multirow{2}{*}{ Non-Political Out-Party } & $5.45^{*}$ & $-4.61^{*}$ \\
\hline & $(1.13)$ & $(1.38)$ \\
\hline$N$ & 3290 & 3290 \\
\hline \multicolumn{3}{|c|}{ Reference category is no news exposure } \\
\hline \multicolumn{3}{|c|}{ Models control for party and survey wave } \\
\hline \multicolumn{3}{|l|}{ Standard errors in parentheses } \\
\hline${ }^{*}$ indicates significance at $p<$ & & \\
\hline
\end{tabular}

We now consider these effects separately for Democrats and Republicans. We observe a consistent pattern to the overall results, but there is some heterogeneity as the effects are larger for Republicans than for Democrats. This may speak to a greater difficulty in moving Democrats' views of Fox News given the network's reputation also reflects the coverage it provides on cable television, while Huffington Post is only available online. 
Table E2: Pooled Effects of Non-Political Exposure on Views of Out-Party Media (Experiments 1 and 2) - Democrats Only

\begin{tabular}{lcc}
\hline & Out-Party Media & Difference \\
\hline (Intercept) & $40.31^{*}$ & $20.73^{*}$ \\
& $(1.73)$ & $(2.03)$ \\
Non-Political Out-Party & $3.76^{*}$ & -1.96 \\
& $(1.63)$ & $(1.92)$ \\
\hline$N$ & 1836 & 1836 \\
\hline Reference category is no news exposure & \\
Models control for survey wave & \\
Standard errors in parentheses & \\
$*$ indicates significance at $p<0.05$ & &
\end{tabular}

Table E3: Pooled Effects of Non-Political Exposure on Views of Out-Party Media (Experiments 1 and 2) - Republicans Only

\begin{tabular}{|c|c|c|}
\hline & Out-Party Media & Difference \\
\hline \multirow{2}{*}{ (Intercept) } & $44.07^{*}$ & $21.54^{*}$ \\
\hline & $(1.64)$ & $(2.14)$ \\
\hline \multirow[t]{2}{*}{ Non-Political Out-Party } & $7.60^{*}$ & $-7.97^{*}$ \\
\hline & $(1.50)$ & $(1.96)$ \\
\hline$N$ & 1454 & 1454 \\
\hline \multicolumn{3}{|c|}{ Reference category is no news exposure } \\
\hline \multicolumn{3}{|l|}{ Models control for survey wave } \\
\hline \multicolumn{3}{|l|}{ Standard errors in parentheses } \\
\hline${ }^{*}$ indicates significance at $p<$ & .05 & \\
\hline
\end{tabular}

\section{E.2 Pooled Effects of Neutral Political Exposure}

Experiments 2 and 3 compare exposure to hostile coverage from an out-party source and neutral coverage from an out-party source. We pool these conditions in Table E4. Again, we find similar results. Both in terms of improving views of the out-party media outlet and reducing the divide between a respondent's assessment of in-party and out-party media sources, exposure to neutral political coverage reduces oppositional media hostility. 
Table E4: Pooled Effects of Neutral Political Exposure on Views of Out-Party Media (Experiments 2 and 3 )

\begin{tabular}{lcr}
\hline \multicolumn{2}{c}{ Out-Party Media } & Difference \\
\hline (Intercept) & $14.68^{*}$ & $50.83^{*}$ \\
& $(0.88)$ & $(1.20)$ \\
Neutral Out-Party & $3.06^{*}$ & $-3.21^{*}$ \\
& $(0.68)$ & $(0.94)$ \\
\hline$N$ & 4336 & 4336 \\
\hline Reference category is hostile out-party news exposure \\
Models control for party, pre-treatment views of out-party media and survey wave \\
Standard errors in parentheses & \\
$*$ indicates significance at $p<0.05$ &
\end{tabular}

Next, we separate the analysis by party in Table E5 and Table E6. We observe a similar pattern in which these treatments have a stronger influence on Republicans than Democrats, although the directions of these treatment effects are the same among both sets of partisans. Table E5: Pooled Effects of Neutral Political Exposure on Views of Out-Party Media (Experiments 2 and 3) - Democrats Only

\begin{tabular}{lcc}
\hline & Out-Party Media & Difference \\
\hline (Intercept) & $12.58^{*}$ & $49.22^{*}$ \\
& $(0.94)$ & $(1.20)$ \\
Neutral Out-Party & $2.64^{*}$ & $-2.62^{*}$ \\
& $(0.90)$ & $(1.15)$ \\
\hline$N$ & 2517 & 2517 \\
\hline
\end{tabular}

Reference category is hostile out-party news exposure

Models control for pre-treatment views of out-party media and survey wave

Standard errors in parentheses

* indicates significance at $p<0.05$ 
Table E6: Pooled Effects of Neutral Political Exposure on Views of Out-Party Media (Experiments 2 and 3) - Republicans Only

\begin{tabular}{lcc}
\hline \multicolumn{2}{c}{ Out-Party Media } & Difference \\
\hline (Intercept) & $17.26^{*}$ & $48.17^{*}$ \\
& $(1.16)$ & $(1.76)$ \\
Neutral Out-Party & $3.57^{*}$ & $-3.96^{*}$ \\
\multicolumn{2}{c}{$(1.03)$} & 1819 \\
\hline$N$ & 1819 & \\
\hline Reference category is hostile out-party news exposure \\
Models control for pre-treatment views of out-party media and survey wave \\
Standard errors in parentheses
\end{tabular}

